\title{
Climate-soil-vegetation control on groundwater table dynamics and its feedbacks in a climate model
}

\author{
L. Ruby Leung $\cdot$ Maoyi Huang $\cdot$ Yun Qian • \\ Xu Liang
}

Received: 14 April 2009/Accepted: 7 January 2010/Published online: 29 January 2010

(C) The Author(s) 2010. This article is published with open access at Springerlink.com

\begin{abstract}
Among the three dynamically linked branches of the water cycle, including atmospheric, surface, and subsurface water, groundwater is the largest reservoir and an active component of the hydrologic system. Because of the inherent slow response time, groundwater may be particularly relevant for long time-scale processes such as multi-years or decadal droughts. This study uses regional climate simulations with and without surface watergroundwater interactions for the conterminous US to assess the influence of climate, soil, and vegetation on groundwater table dynamics, and its potential feedbacks to regional climate. Analyses show that precipitation has a dominant influence on the spatial and temporal variations of groundwater table depth (GWT). The simulated GWT is found to decrease sharply with increasing precipitation. Our simulation also shows some distinct spatial variations that are related to soil porosity and hydraulic conductivity. Vegetation properties such as minimum stomatal resistance, and root depth and fraction are also found to play an important role in controlling the groundwater table. Comparing two simulations with and without groundwater table dynamics, we find that groundwater table dynamics
\end{abstract}

L. R. Leung $(\varangle) \cdot$ M. Huang · Y. Qian

Pacific Northwest National Laboratory,

Richland, WA, USA

e-mail: Ruby.Leung@pnl.gov

X. Liang

University of Pittsburgh, Pittsburgh, PA, USA

X. Liang

State Key Laboratory of Hydraulics and Mountain River

Engineering, Sichuan University, Chengdu, China mainly influences the partitioning of soil water between the surface $(0-0.5 \mathrm{~m})$ and subsurface $(0.5-5 \mathrm{~m})$ rather than total soil moisture. In most areas, groundwater table dynamics increases surface soil moisture at the expense of the subsurface, except in regions with very shallow groundwater table. The change in soil water partitioning between the surface and subsurface is found to strongly correlate with the partitioning of surface sensible and latent heat fluxes. The evaporative fraction $(\mathrm{EF})$ is generally higher during summer when groundwater table dynamics is included. This is accompanied by increased cloudiness, reduced diurnal temperature range, cooler surface temperature, and increased cloud top height. Although both convective and non-convective precipitation are enhanced, the higher EF changes the partitioning to favor more non-convective precipitation, but this result could be sensitive to the convective parameterization used. Compared to simulations without groundwater table dynamics, the dry bias in the summer precipitation is slightly reduced over the central and eastern US Groundwater table dynamics can provide important feedbacks to atmospheric processes, and these feedbacks are stronger in regions with deeper groundwater table, because the interactions between surface and subsurface are weak when the groundwater table is deep. This increases the sensitivity of surface soil moisture to precipitation anomalies, and therefore enhances land surface feedbacks to the atmosphere through changes in soil moisture and evaporative fraction. By altering the groundwater table depth, land use change and groundwater withdrawal can alter land surface response and feedback to the climate system.

Keywords Climate - Groundwater table dynamics . Land-atmosphere feedbacks · Regional climate modeling 


\section{Introduction}

Among the three dynamically linked branches of the water cycle, including atmospheric, surface, and subsurface water, groundwater is the largest reservoir and an active component of the hydrologic system. Groundwater also provides up to $90 \%$ of drinking and irrigation water across different parts of the United States. Although groundwater discharge and recharge are important components of the terrestrial water cycle, relatively little is known about the impacts of groundwater on the climate system (National Research Council 2003). Because of the inherent slow response time, groundwater may be particularly relevant for long time-scale processes such as multi-years or decadal droughts.

Groundwater storage, recharge, and discharge can play a significant role in the climate system through its interactions with surface water that influences the surface energy and water exchange with the atmosphere. A rising groundwater table, for example, may increase soil moisture, evapotranspiration, and streamflow to potentially alter regional climate, and a declining groundwater table may have an opposite effect (National Research Council 2003). In addition, changes in water budgets on the longer time scale may affect the distribution of vegetation and ecosystems, which may further influence the climate system. Although the influence of the climate system and land cover and land use on groundwater may be more obvious, their combined effects on groundwater table is not well understood or quantified at the regional to global scale.

Our current knowledge of the interactions between the climate system and groundwater table is limited because it is difficult to measure groundwater recharge and discharge in situ with reasonable spatial extent and resolution over multiple years (e.g., Scanlon et al. 2002; Sophocleous 2004). Remote sensing techniques are only partially effective at present due to their shallow penetration into the ground (e.g., Jackson 2002) or very coarse spatial resolutions (e.g., Rodell and Famiglietti 2001). Modeling climate, land surface processes, and surface and subsurface hydrology as an integrated system remains a significant challenge, partly because these processes operate and are modeled at very different temporal and spatial scales. For example, climate is typically modeled at the regional to global scale on seasonal to decadal time scales, while subsurface hydrology is traditionally modeled at the hillslope to catchment scale (e.g., Salvucci and Entekhabi 1995) on decadal to century time scales.

Early efforts to incorporate groundwater processes in macroscale hydrologic or land surface models have often adopted the concept of TOPMODEL (Beven and Kirby 1979), which considers the effects of topography and groundwater table on the water and energy budgets, and groundwater table is modeled under steady or quasi-steady states (Walko et al. 2000). More recently, three-dimensional (e.g., Gutowski et al. 2002) and one-dimensional (i.e., models of independent soil column) (e.g., Liang et al. 2003; Chen and Hu 2004; Maxwell and Miller 2005; Niu et al. 2006; Fan et al. 2007; Miguez-Macho et al. 2007) groundwater models have been implemented in land surface models to simulate groundwater table and recharge/ discharge dynamically. Most studies reported results based on offline simulations driven by observed atmospheric conditions. Because land-atmosphere interactions cannot be represented in offline models, these studies have focused on evaluating the various surface water components simulated by the offline models using observations and assessing the impacts of representing groundwater on the surface water budgets. For example, comparison of offline simulations with and without the dynamic groundwater representation shows a 4-16\% change in evapotranspiration (ET) globally (Niu et al. 2006), and more realistic depictions of root zone soil moisture and runoff when the dynamic groundwater component was included (Maxwell and Miller 2005).

More recently, the impacts of groundwater on climate have been studied by Anyah et al. (2008), Yuan et al. (2008), and Jiang et al. (2009) using regional climate models with coupled land-atmosphere processes and a groundwater component applied to the US and China. They found that groundwater table dynamics can influence ET and precipitation through land-atmosphere coupling. While Anyah et al. (2008) and Jiang et al. (2009) reported more groundwater table induced ET and precipitation changes in relatively dry regions through local precipitation recycling, Yuan et al. (2008) found that in addition to local recycling effects in semi-arid regions, large increase in precipitation is also found in humid and semi-humid regions due to groundwater table induced changes in largescale circulation. As China is strongly influenced by the East Asian summer monsoon, the influence of groundwater table dynamics on monsoon rainfall was found to be quite significant by Yuan et al. (2008). All studies, however, cautioned that their results were based on short simulations of specific summer seasons (from May to October 1997 in Anyah et al.; June-August 2000 in Yuan et al., and JuneAugust 2002 in Jiang et al.). Because all studies focused mainly on the warm season regime, their results on groundwater table influence on precipitation are particularly sensitive to the convective parameterization used. In addition, by focusing only on the summer seasons, the impacts of cold season groundwater table variations on land-atmosphere interactions in the summer are ignored.

This paper describes a modeling system to simulate the dynamic surface water and groundwater interactions and land-atmosphere feedbacks at the regional scale. The 
modeling system includes an atmospheric model fully coupled with a land surface model that represents both surface and subsurface hydrological processes. While our ultimate goal is to apply the modeling system to study the role of surface water and groundwater interactions on long term droughts, this paper documents our modeling approach, identifies the critical data needs for more realistic simulations of groundwater fluctuations, and contributes to our understanding of the interactions between the climate system and groundwater table dynamics in the US that displays a wide range of climate regimes that differ in the timing, amount, and phase of seasonal precipitation as well as sources of moisture (i.e., local recycling vs. large-scale transport). More specifically, we performed multi-year simulations for all seasons and the results are analyzed to determine how climate and land surface property influence groundwater table fluctuations, and how groundwater table dynamics changes the surface water budgets and affect regional climate through landatmosphere interactions.

\section{Model description}

\subsection{MM5-VIC coupling}

This study used a regional climate model based on the Penn State/NCAR Mesoscale Model MM5 (Grell et al. 1994). The model has been applied to the US (Leung et al. 2003) and East Asia (Qian and Leung 2007) and found to realistically simulate the hydroclimate conditions in widely different climate regimes. The model is fully coupled to a land surface component based on the Three-layer Variable Infiltration Capacity model (VIC-3L) (Liang et al. 1994, 1996, 1999, 2003; Liang and Xie 2001; Cherkauer and Lettenmaier 2003). VIC has several distinguishing features including the representation of subgrid spatial variability of soil properties and precipitation, and their influence on both infiltration and saturation excess runoff.

As described by Liang et al. (2006), the coupling of MM5 and VIC was achieved in a way similar to that described by Chen and Dudhia (2001), who coupled MM5 to the OSU land surface model through the model's lowest level, which is represented by a surface layer parameterization that provides surface exchange coefficients for momentum, heat, and moisture to determine their fluxes between the land surface and the atmosphere. The surface layer parameterization is handled through the nonlocal boundary layer scheme of Troen and Mahrt (1986), inside which the land surface model is called through an argument list. The VIC model used to couple with MM5 has been extensively modified to adopt a "space before time" structure, as opposed to the "time before space" structure.
In the offline VIC that uses the "time before space" structure, time integration is performed one grid cell at a time for the whole simulation period before time integration for the next grid cell begins. The change to the "space before time" structure is necessary for coupling VIC with any atmospheric models such as MM5 that are spatially distributed.

In the coupled model, most vegetation and soil parameters are determined through lookup tables (Chen and Dudhia 2001) of land cover type and soil texture type, which are determined by the MM5 preprocessor for each model grid cell based on the 1-km resolution Advanced Very High Resolution Radiometer (AVHRR) satellite data defined for 24 USGS land cover categories, and the 1-km resolution multilayer 16 category soil characteristics dataset of Miller and White (1998), respectively. A single land cover category and soil category based on the dominant type is assigned to each model grid cell, but subgrid surface heterogeneity can be represented in the future using the elevation/land cover class approach of Liang et al. (1994) implemented in VIC and Leung and Ghan (1998) implemented in MM5. Tables 1 and 2 list some vegetation and soil parameters that are used in the model. As discussed by Chen and Dudhia (2001), the vegetation parameters are taken from many different sources (e.g., Dorman and Sellers 1989; Dickinson et al. 1993; Mahfouf et al. 1995). Seasonal variations of vegetation cover are captured by the monthly leaf area index (LAI) defined by VIC. Soil parameters including porosity, saturated metric potential, saturated hydraulic conductivity, and slope of the retention curve are specified from the soil analysis of Cosby et al. (1984). We noted, however, that the hydraulic conductivity for sand is prescribed at a much lower value in MM5 than Cosby et al. based on previous tuning results (Fei Chen, personal communication). Because only a very small fraction of the grid cells are assigned the soil texture of sand, the impacts on our simulations should be minimal.

VIC requires several parameters that are not provided by the MM5 preprocessor. These include the b-parameter that measures the subgrid variability of the soil moisture capacity and three other parameters, $D_{\mathrm{s}}, D_{\text {smax }}$, and $W_{\mathrm{s}}$, which are associated with the ARNO subsurface flow formation (Francini and Pacciani 1991; Todini 1996). In typical offline VIC applications, these parameters are calibrated using streamflow data for the study watersheds. In this study where VIC is coupled to a climate model and applied over a large geographic region, this tuning is not performed. Therefore, the b-parameter, $D_{\mathrm{s}}$, and $W_{\mathrm{s}}$ are currently set using typical values regardless of geographical locations, while $D_{\text {smax }}$ was estimated as a product of the saturated hydraulic conductivity and the slope of the grid cell. Because of the relatively large model grid size used in our simulations, we prescribed a uniform slope of 0.005 . 
Table 1 Vegetation related parameters for 24 USFS vegetation types used in MM5

\begin{tabular}{|c|c|c|c|c|c|}
\hline Vegetation type & $\alpha$ & $Z_{\mathrm{o}}$ & $R_{\mathrm{sm}}$ & Root depth (m) & Root fraction \\
\hline 1. Urban and built-up land & 18 & 50 & 200 & $0.01,0.01,0.03$ & $0.80,0.10,0.10$ \\
\hline 2. Dryland crop and pasture & 17 & 15 & 40 & $0.10,0.40,0.20$ & $0.43,0.36,0.21$ \\
\hline 3. Irrigated crop and pasture & 18 & 15 & 40 & $0.10,0.40,0.20$ & $0.43,0.36,0.21$ \\
\hline 4. Mixed crop and pasture & 18 & 15 & 40 & $0.10,0.40,0.20$ & $0.43,0.36,0.21$ \\
\hline 5. Crop/grass mosaic & 18 & 14 & 40 & $0.10,0.40,0.20$ & $0.43,0.36,0.21$ \\
\hline 6. Crop/woodland mosaic & 16 & 20 & 70 & $0.10,0.40,0.20$ & $0.43,0.36,0.21$ \\
\hline 7. Grassland & 19 & 12 & 40 & $0.10,0.40,0.20$ & $0.50,0.36,0.14$ \\
\hline 8. Shrubland & 22 & 10 & 300 & $0.10,0.40,0.20$ & $0.44,0.37,0.19$ \\
\hline 9. Mixed shrub/grass & 20 & 11 & 170 & $0.10,0.40,0.20$ & $0.44,0.37,0.19$ \\
\hline 10. Savanna & 20 & 15 & 70 & $0.10,0.40,0.20$ & $0.34,0.53,0.13$ \\
\hline 11. Deciduous broadleaf forest & 16 & 50 & 100 & $0.10,0.40,1.00$ & $0.076,0.84,0.084$ \\
\hline 12. Deciduous needleleaf forest & 14 & 50 & 150 & $0.10,0.40,1.00$ & $0.076,0.84,0.084$ \\
\hline 13. Evergreen broadleaf forest & 12 & 50 & 150 & $0.10,0.40,1.00$ & $0.076,0.84,0.084$ \\
\hline 14. Evergreen needleleaf forest & 12 & 50 & 125 & $0.10,0.40,1.00$ & $0.076,0.84,0.084$ \\
\hline 15. Mixed forest & 13 & 50 & 125 & $0.10,0.40,1.00$ & $0.076,0.84,0.084$ \\
\hline 16. Water bodies & 8 & 0.01 & 100 & $0.00,0.00,0.00$ & $0.00,0.00,0.00$ \\
\hline 17. Herbaceous wetland & 14 & 20 & 40 & $0.10,0.40,0.20$ & $0.80,0.10,0.10$ \\
\hline 18. Wooded wetland & 14 & 40 & 100 & $0.10,0.40,0.20$ & $0.43,0.36,0.21$ \\
\hline 19. Barren or sparsely vegetated & 25 & 10 & 999 & $0.01,0.01,0.03$ & $0.80,0.10,0.10$ \\
\hline 20. Herbaceous tundra & 15 & 10 & 150 & $0.10,0.40,0.20$ & $0.43,0.36,0.21$ \\
\hline 21. Wooded tundra & 15 & 30 & 150 & $0.10,0.40,0.20$ & $0.44,0.37,0.19$ \\
\hline 22. Mixed tundra & 15 & 15 & 150 & $0.10,0.40,0.20$ & $0.44,0.37,0.19$ \\
\hline 23. Bare ground tundra & 25 & 10 & 200 & $0.10,0.10,0.05$ & $0.80,0.10,0.10$ \\
\hline 24. Snow or ice & 55 & 5 & 999 & $0.00,0.00,0.00$ & $0.00,0.00,0.00$ \\
\hline
\end{tabular}

Listed above are selected parameters including surface albedo $(\alpha)$, roughness length $(\mathrm{cm})$, minimum stomatal resistance $(\mathrm{s} / \mathrm{m})$, root depth $(\mathrm{m})$, and root fraction for the three VIC soil layers. The first three parameters are season dependent; only values for the summer are shown

Table 2 Soil porosity and hydraulic conductivity of 16 soil types used to define the soil properties of each model grid cell

\begin{tabular}{lll}
\hline Soil type and group & $\begin{array}{l}\text { Soil porosity } \\
\left(\mathrm{m}^{3} \mathrm{~m}^{-3}\right)\end{array}$ & $\begin{array}{l}\text { Hydraulic conductivity } \\
\left(\mathrm{m} \mathrm{s}^{-1}\right)\end{array}$ \\
\hline 1. Sand & 0.339 & $1.06 \mathrm{E}-6$ \\
2. Loamy sand & 0.421 & $1.41 \mathrm{E}-5$ \\
3. Sandy loam & 0.434 & $5.23 \mathrm{E}-6$ \\
4. Silt loam & 0.476 & $2.81 \mathrm{E}-6$ \\
5. Silt & 0.476 & $2.81 \mathrm{E}-6$ \\
6. Loam & 0.439 & $3.38 \mathrm{E}-6$ \\
7. Sandy clay loam & 0.404 & $4.45 \mathrm{E}-6$ \\
8. Silty clay loam & 0.464 & $2.04 \mathrm{E}-6$ \\
9. Clay loam & 0.465 & $2.45 \mathrm{E}-6$ \\
10. Sandy clay & 0.406 & $7.22 \mathrm{E}-6$ \\
11. Silty clay & 0.468 & $1.34 \mathrm{E}-6$ \\
12. Clay & 0.468 & $9.74 \mathrm{E}-7$ \\
13. Organic material & 0.439 & $3.38 \mathrm{E}-6$ \\
14. Water & NA & NA \\
15. Bedrock & 0.25 & $9.74 \mathrm{E}-8$ \\
16. Other (land-ice) & 0.421 & $1.34 \mathrm{E}-6$ \\
\hline
\end{tabular}

Given the saturated hydraulic conductivities in Table 2, $D_{\text {smax }}$ ranges from 0.4 to $61.0 \mathrm{~mm} /$ day, which fall within the reasonable range for this parameter. However, it might underestimate subsurface flow at grid cells with large topographic relieves, and overestimate subsurface flow over flat regions. In the future, the technique of Huang et al. (2003) can be used to determine the spatial distribution of the VIC parameters based on soil properties described in the STATSGO dataset and DEM data.

\subsection{Representation of surface water-groundwater interactions}

Four types of approaches have been used in recent studies to simulate the dynamic movement of groundwater table in climate models. The simplest and most common approach is the TOPMODEL based formulation that simulates the groundwater table at quasi-equilibrium state (e.g., Walko et al. 2000). More recently, methods have been developed to solve the soil moisture of unsaturated zone and pressure head profiles of saturated zones by applying the Richards equation or its variations to each zone separately 
(e.g., Gutowski et al. 2002; York et al. 2002; Fan et al. 2007; Niu et al. 2006). These approaches are also computationally efficient, but interactions between surface water and groundwater cannot be fully represented due to its one-way coupling nature-that is, equations for the unsaturated and saturated zones are solved independently.

Two-way coupling approaches have also been explored in recent years. In this type of approach, the hydraulic pressure profile for the unsaturated and saturated zones are solved together (i.e., two-way coupling) based on a mixed form of the Richards equation (e.g., Yeh and Eltahir 2005a, 2005b; Maxwell and Miller 2005). The saturated zone and groundwater table is automatically determined in the soil column when the pressure head is $\geq 0$ and saturation is $100 \%$. Alternatively, Liang et al. (2003) developed a twoway coupling approach using a moving boundary. Their method solves the soil moisture profile by applying the Richards equation to the unsaturated zone only, with the groundwater table treated as a moving boundary. This approach has the advantage of not introducing any additional parameters other than those already used by a typical land surface model and is computationally more efficient if the groundwater table is not deep because soil moisture is only solved for the unsaturated zone. Both of the two-way coupling approaches can better represent the comprehensive dynamic interactions between surface water and groundwater.

The version of VIC-3L that is coupled to MM5 includes a new module that represents the dynamic movements of groundwater table using the approach of Liang et al. (2003). The Richards equation is solved using the finite element method so it allows a flexible and, if needed, a large number of soil layers in the model structure for soil column to facilitate interactions between groundwater table, soil moisture, and plant roots. In this study, a soil depth of $5 \mathrm{~m}$ is prescribed for each grid because information about bedrock depth (or soil depth) is very limited. The STATSGO data, for example, do not provide information about bedrock that is below 60 in. $(152 \mathrm{~cm})$ from the surface. While the use of a uniform $5 \mathrm{~m}$ soil depth limits the groundwater table depth to $5 \mathrm{~m}$, which is unrealistic for arid and semi-arid regions, the use of much deeper soil depth can bias the simulated soil moisture and seasonal runoff unless the VIC model parameters are recalibrated using offline simulations and observations. In a recent study, Maxwell and Kollet (2008) used a detailed integrated groundwater/surface-water/land-surface model to study the interdependence of groundwater dynamics and land-energy feedbacks under climate change. Applying their model with a very deep subsurface of about $100 \mathrm{~m}$ to a watershed in the southern Great Plains in Oklahoma, they found very strong correlations between groundwater table depth and land-surface response in a "critical zone" between 2 and $5 \mathrm{~m}$ below the surface. In other words, landsurface and subsurface processes are most tightly coupled in the critical zone; when the groundwater table is above $2 \mathrm{~m}$ or below $5 \mathrm{~m}$, land surface response is insensitive to the groundwater table depth (e.g., Fig. 2 of Maxwell and Kollet shows no difference in latent heat flux or recharge for regions with a $5 \mathrm{~m}$ deep groundwater table compared to regions with groundwater table deeper than $5 \mathrm{~m}$ ). Because our goal is to simulate land surface response to groundwater table dynamics, rather than to simulate a realistic spatial distribution of groundwater table depth, the results of Maxwell and Kollet suggest that setting a uniform $5 \mathrm{~m}$ soil depth in this study does not compromise our goal, although groundwater table depth below $5 \mathrm{~m}$ cannot be simulated by the model. In this study, we assess both the impacts of soil depth and the use of dynamic groundwater component to better quantify their effects on the simulations. This should provide an important foundation for future work using spatially variable soil depth when such data become available at the larger scale suitable for regional and global climate modeling.

The soil column in the VIC groundwater module is discretized into 100 soil layers, each $5 \mathrm{~cm}$ thick, to allow more accurate estimation of groundwater table (GWT). However, only the soil layers between the land surface and the simulated groundwater table are used in the computation; all the soil layers beneath the groundwater table are considered saturated. Different time steps are used in the groundwater module and the original VIC-3L calculations. In VIC-3L, all the fluxes (e.g., evapotranspiration, surface runoff, subsurface runoff, etc.) and soil moisture content of the three soil layers are computed at the same time step as the atmospheric model (e.g., 2 min for a grid resolution of $60 \mathrm{~km}$ ). In the groundwater module, the 100-layer soil moisture profile is updated with an hourly time step. At the end of each hour, soil moisture of the three VIC soil layers is updated to be consistent with the soil moisture aggregated from the soil moisture profile calculated by the groundwater module to the three VIC soil layers. The use of a larger time step in the groundwater module can significantly reduce the computational time when the groundwater module is included.

The groundwater table is initialized uniformly within the study domain at $2 \mathrm{~m}$ below the surface. Based on offline VIC simulations, Liang et al. (2003) found that the GWT converges faster to its final value with a shallower initial GWT depth than a deeper initial GWT depth. For example, in their offline simulations, it took about 3 years for the GWT depth to converge when a deeper initial GWT depth is used, compared to less than 1.5 years when a shallower initial GWT depth is used. For the simulations described below, we found that the GWT depth generally stabilized within the first 4 years of the simulation with a $5 \mathrm{~m}$ soil 
depth and a $2 \mathrm{~m}$ initial GWT depth. The initial soil moisture profile corresponding to the prescribed initial groundwater table is obtained through iteration (see Liang et al. 2003 for details).

\section{Numerical experiments}

To examine the impacts of simulating groundwater table dynamically, three simulations were performed using MM5 over the conterminous US at $60 \mathrm{~km}$ spatial resolution and 23 vertical levels. In the first two control simulations, called CON-2 and CON-5, soil depth is prescribed at 2 and $5 \mathrm{~m}$, respectively, and the dynamic groundwater component is not used. The top two soil layers are defined at soil depths of 0.1 and $0.4 \mathrm{~m}$, while the third layer has a depth of 1.5 and $4.5 \mathrm{~m}$, respectively, for CON-2 and CON-5. A third simulation, called GW-5, was performed with the same soil depth as CON-5 and included the dynamical groundwater component. The soil depth of $5 \mathrm{~m}$ will allow deeper groundwater table to be simulated. Because VIC was mostly applied using a $2 \mathrm{~m}$ soil depth in the past, the two control simulations were performed to compare the effects of different soil depths, and establish a simulation (CON-5) that can be compared with GW-5 to isolate the impacts of including a dynamic groundwater component alone. In all simulations, the same spatial distribution of vegetation (including root depth and root fraction) and soil texture were used.

The simulations covered a 16-year period from 1 June 1986 to 30 September 2002. The NCEP/DOE global reanalysis (Kanamitsu et al. 2002) and AMIP sea surface temperature (Taylor et al. 2000) were used to provide large-scale atmospheric boundary conditions and lower boundary conditions that were updated every $6 \mathrm{~h}$ during the simulations. The same set of physics parameterizations tested in Leung et al. (2003) was used, with the exception of the land surface model, which was replaced by VIC-3L. The GW component was called every hour during the simulation, while VIC was called every MM5 time step ( $2 \mathrm{~min}$ ). The $\mathrm{GW}$ run requires about $30 \%$ more computing time compared to the control runs.

To facilitate comparison between the simulations, state variables in the $5 \mathrm{~m}$ soil column of GW-5 are mapped to the three soil layers of CON-5 with thickness of $0.1,0.4$, and $4.5 \mathrm{~m}$ for comparison. Regional averages are calculated based on areas defined by boundaries of river basins. A total of 13 regions, as shown in Fig. 1, are used in our analyses. Comparisons are made between GW-5 and the control runs, and evaluated using observed $1 / 8^{\circ}$ gridded temperature and precipitation data. We also used monthly mean runoff data from stream gauges (Gao et al. 2009) and the University of New Hampshire Global Runoff Data Centre (UNH-GRDC) for comparison with the simulated runoff in large river basins. We obtained groundwater table data for unconfined aquifer, groundwater wells from USGS National Water Information System (http://pubs.usgs.gov/ of/2004/1238/) for a qualitative comparison with the simulated water table depth. The Gravity Recovery and Climate Experiment (GRACE) (Rodell et al. 2004; Chambers 2006) satellites derived terrestrial water storage anomaly $(\Delta S)$ are used to evaluate the long term mean seasonal variations of terrestrial water storage simulated by the model. Three sets of estimates from GRACE data developed by Center for Space Research (CSR) at University of Texas, GFZ German Research Center, and Jet Propulsion Laboratory (JPL) averaged over 13 river basins are used (Gao et al. 2009). In addition, soil moisture profiles from eight
Fig. 1 The boundaries of 13 regions used in analysis of observations and model simulations. Most regions follow the boundaries of major river basins in the US
13 sub-regions based on UW data

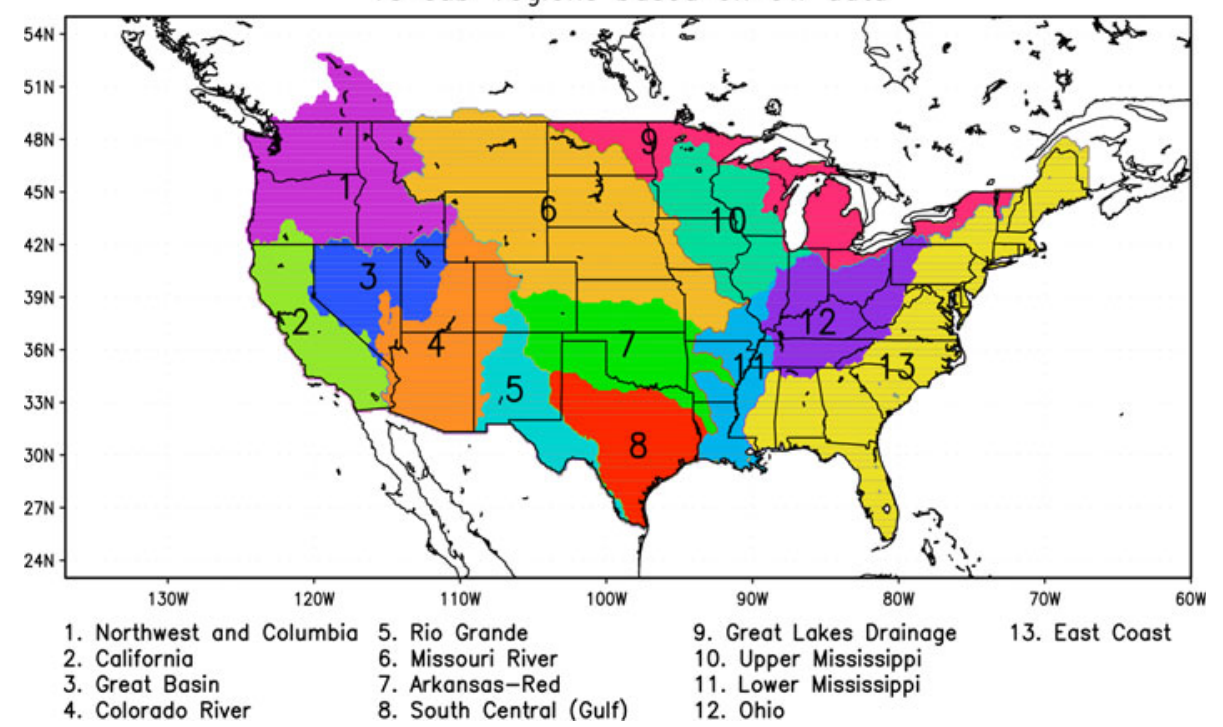


AmeriFlux stations are used for comparison with the simulated soil moisture profiles in the GW-5 simulation.

From time series of the simulated groundwater table depth, we noted in Sect. 2.2 that the groundwater table generally stabilized after less than 4 years of model spin up; therefore results for the last 12 years are used for analysis and model evaluation. Figure 2 compares the observed and simulated mean monthly precipitation averaged over the last 12 years (1990/3-2002/2) of the simulations (CON-2, CON-5, and GW-5) for the 13 regions shown in Fig. 1. Generally, the simulation realistically captured the spatial and seasonal variability. For example, the western US is marked by a distinct seasonal cycle with more precipitation in NW/Columbia and California during winter and spring. During the warm season, regions of higher precipitation noticeably shift to the Midwestern and Eastern US However, the simulation shows an obvious dry bias in the central US during summer and fall.

\section{Impacts of soil depth}

A deeper soil column increases the capacity of the soil to store water during precipitation and the wet season, and allows the soil water to be released through runoff and evaporation during dry periods. Thus we expect the impacts of the soil depth to have important influence on soil moisture and runoff. Figure 3 compares the long term averaged surface and subsurface runoff in CON-2, CON-5, and GW-5 averaged over the 13 regions. The most notable differences between the simulations are found between CON-2 and CON-5/GW-5 in regions with strong seasonal changes in precipitation. For example, in NW/Columbia River and California, large surface runoff is found during the wet season (winter) in response to the precipitation, which is also stored in the soil and snowpack in the mountains. Subsequent snowmelt and release of soil moisture during spring supports a relatively high subsurface flow throughout the summer that reaches a minimum in September-October. With a deeper soil column, there is a significant reduction in surface runoff during winter and increase in subsurface runoff in the summer and early fall. Combining the impacts on surface and subsurface runoff, the seasonal cycle of total runoff in CON-5/GW-5 is much reduced, in addition to a broader runoff peak with high runoff lasting through spring.

Similar changes are also found in other regions, but with much smaller magnitude, particularly for relatively dry regions such as the Colorado River and Rio Grande. In regions dominated by subsurface runoff (e.g., the Great Basin, Ohio River, and East Coast), there are also noticeable reductions in the runoff peaks in $\mathrm{CON}-5 / \mathrm{GW}-5$ compared to CON-2, but the changes in peak runoff timing are small. The simulations captured the large regional differences in the total runoff, as well as the ratio of surface to total runoff, and runoff timing, which provide interesting comparisons of the influence of soil depth and dynamic groundwater across different climate and hydrological regimes.

With the increased capacity to store water in a deeper soil column, the total soil moisture in CON-5/GW-5 is generally higher than $\mathrm{CON}-2$, but the differences are mainly found in the third soil layer (below $0.5 \mathrm{~m}$ ) (not shown). For regions with larger seasonal cycles in precipitation and runoff, the differences in soil moisture are small during the wet season, as the soils are near saturation in both simulations, but the differences become larger during the dry season. As a result of soil moisture differences, there are notable differences in sensible and latent heat fluxes, with rather uniform reductions in sensible heat flux and enhancements in latent heat flux by $10-15 \%$ in the central US, and small reductions in surface temperature by up to $1^{\circ}$ during summer in $\mathrm{CON}-5 / \mathrm{GW}-5$ compared to CON-2. This will be elaborated in Sect. 6 to provide insights on the impacts of soil depth on land-atmosphere interactions.

\section{Comparison of observed and simulated land surface water budgets}

Previous studies using offline land surface or hydrologic models have often included more extensive evaluation of the simulated land surface water budgets using observations to assess the skill of the models in capturing important surface and subsurface processes. For coupled land-atmosphere simulations, evaluation of the land surface components is more difficult because variables such as runoff and soil moisture are strongly influenced by precipitation, which is difficult to simulate with high accuracy in current climate models. Therefore, errors in simulating the land surface water budgets are often dominated by model errors in precipitation, making interpretation of the differences between observed and simulated land surface variables more difficult. Nevertheless, it is useful to study the model behaviors in more details, so this section describes some comparisons of our model simulated surface water components with observations to assess the skill of the coupled model to provide guidance for future improvements.

\subsection{Runoff and terrestrial water storage}

Figure 4 shows the model runoff bias for the 13 river basins. Observed runoff data are obtained from USGS stream gauges available for 7 river basins including the 

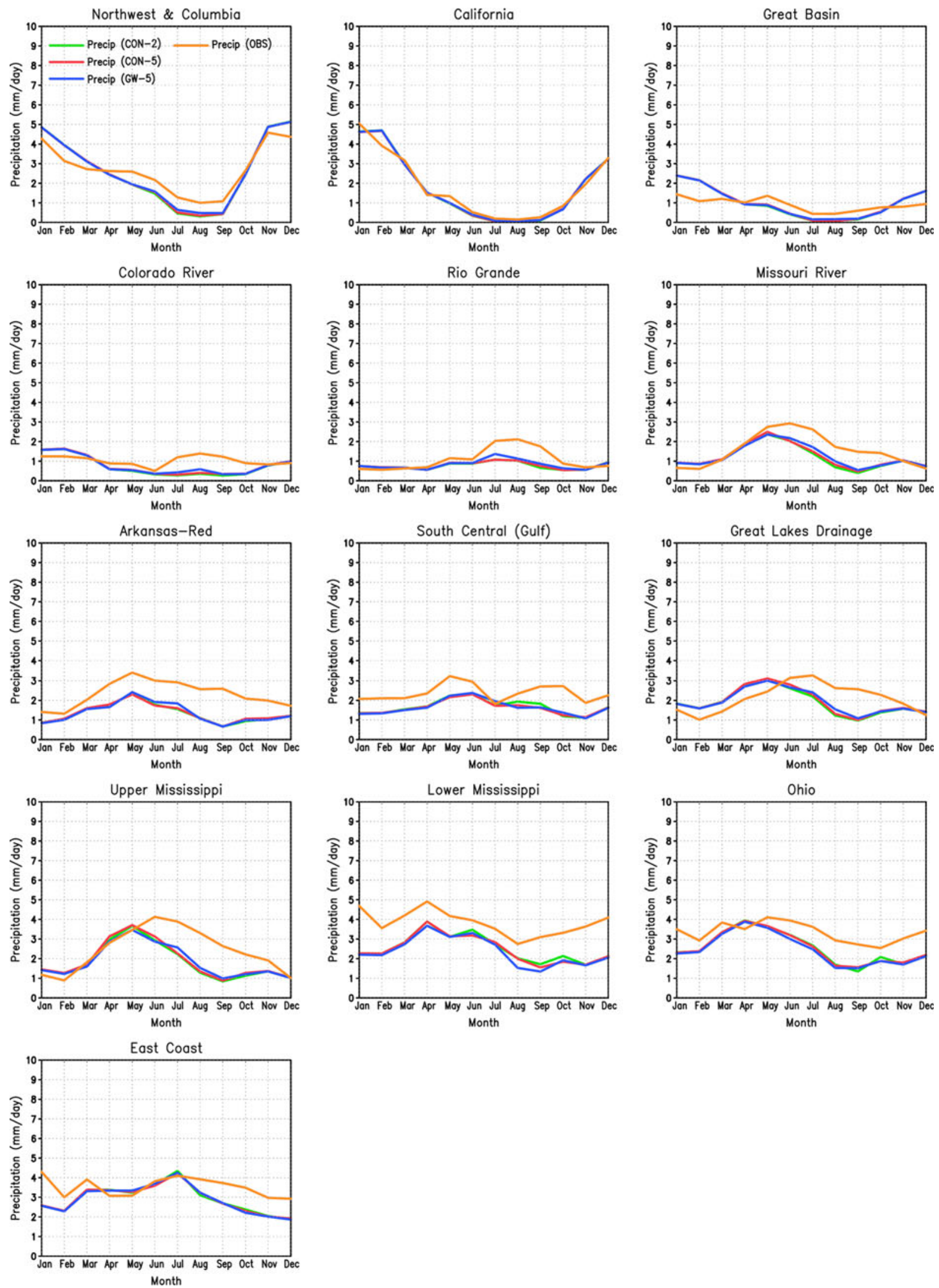

Fig. 2 Mean monthly precipitation from observations (OBS) and model simulations (CON-2, CON-5, and GW-5) averaged over 1990/3-2001/2 in $\mathrm{mm} /$ day for 13 regions 

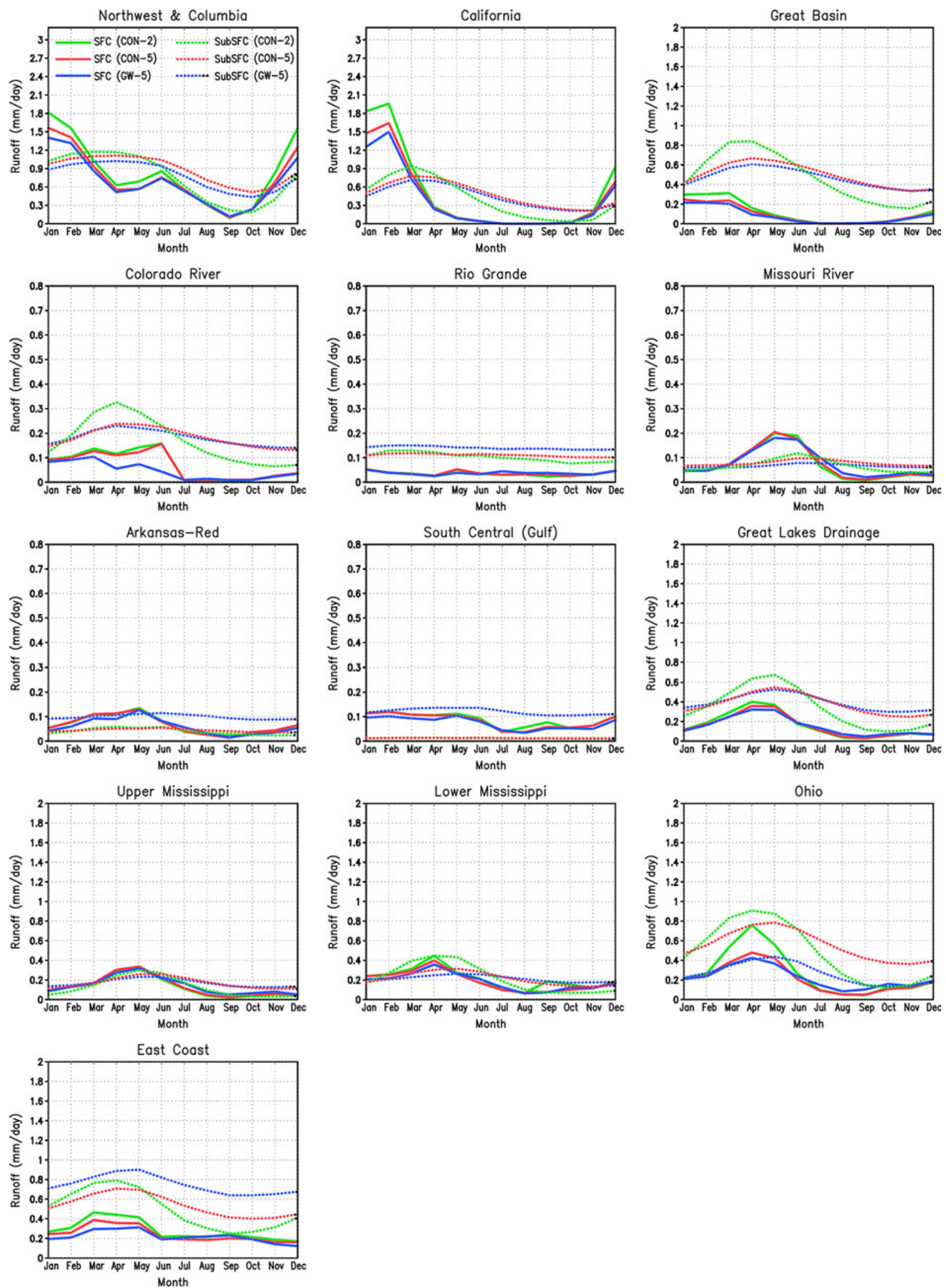

Fig. 3 Mean monthly surface (solid) and subsurface (dashed) runoff for CON-2, CON-5, and GW-5 averaged over 1990/3-2001/2 in mm/day for 13 regions 
Fig. 4 Model runoff bias (in $\mathrm{mm} /$ day) for 13 river basins. Observations are based on stream gauge data (GAUGE) and UNH-GRDC runoff data (GRDC). The model bias from CON-2, CON-5, and GW-5 are shown in green, blue, and red, respectively, when compared with GRDC (solid) and GAUGE (dashed) data. Note that stream gauge data are not available for California, Rio Grande, South Central, Great Lakes, and East Coast
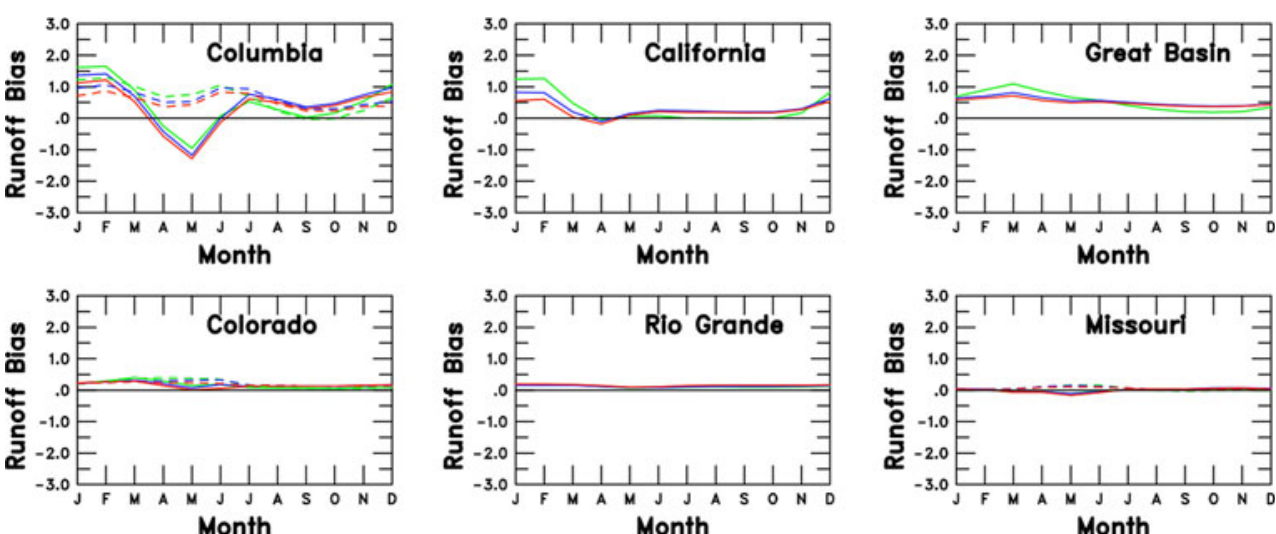

Month
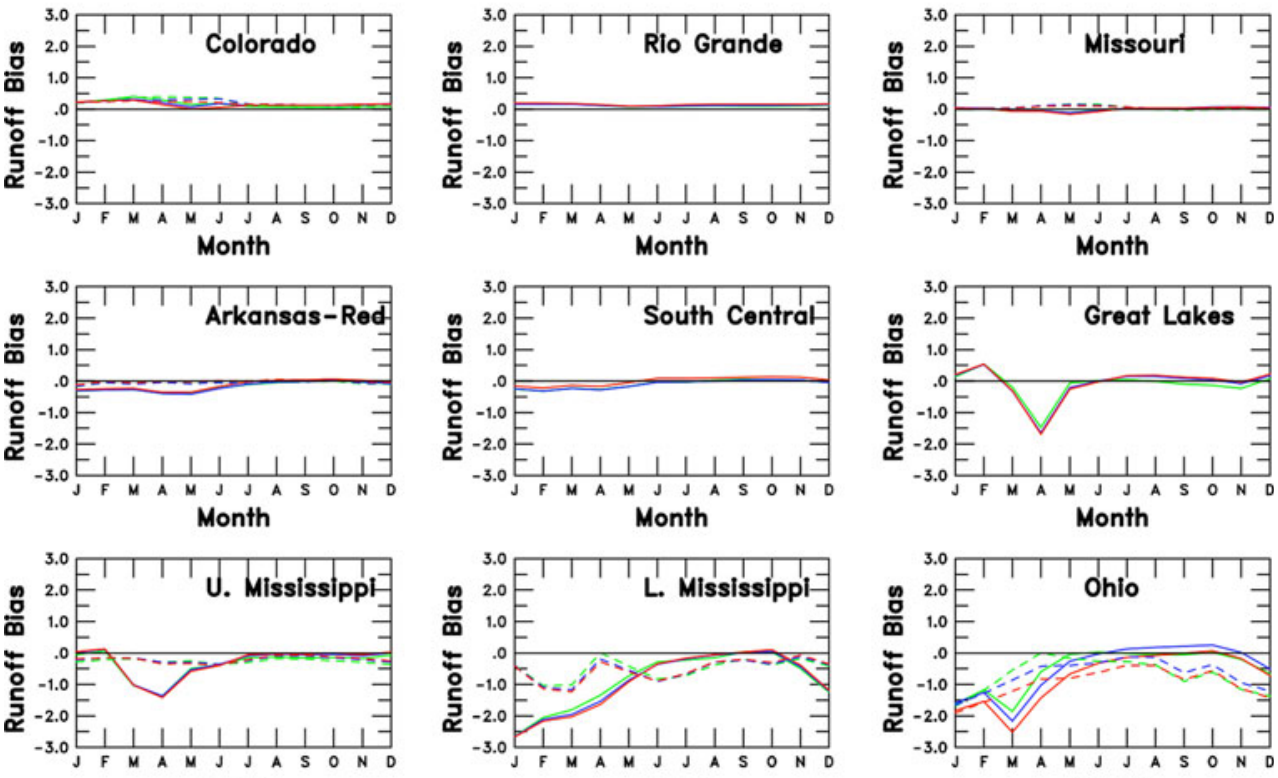

Month
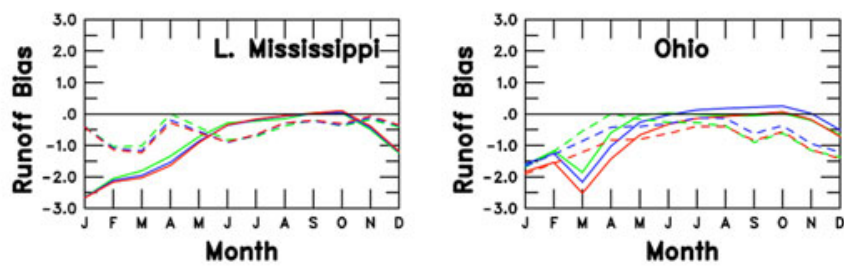

Month

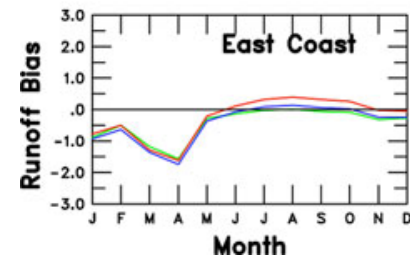

Month
Columbia, Colorado, Missouri, Arkansas-Red, Upper Mississippi, Lower Mississippi, and Ohio River basins. Because stream gauge measurements include the effects of water use, we also include the UNH-GRDC data for comparison. Note that the UNH-GRDC data are outputs from a water balance model driven by observed meteorological data, with corrections using disaggregated observed discharges. Therefore, neither the stream gauge data nor the UNH-GRDC runoff data provide natural flow data that can be used to evaluate model-simulated runoff. We noted that the GRDC data are occasionally below the observed stream gauge data, which indicates potential problems with either dataset. We also caution the comparison of observed runoff with simulated runoff that is not routed, even though on the monthly time scale, the lack of routing may not be significant. Maurer et al. (2002) compared their routed runoff from their offline simulation with naturalized streamflow data and found that the root mean square errors can be reduced by $50 \%$ if the timing of the routed runoff is shifted by $2-3$ weeks.
Figure 4 shows that the total runoff in the three simulations is similar except in wet basins including Columbia, California, and Ohio, where both soil depth (comparing CON-2 and CON5) and groundwater table dynamics (comparing CON-5 and GW-5) make a difference. Overall, relatively good agreement between the observed and simulated runoff is found in California and the Missouri River basins, where the observed (GRDC) peak runoff reaches over 1.5 and $0.4 \mathrm{~mm} /$ day, respectively. In most other basins except in the semi-arid Southwest, the simulated runoff misses the peaks found in the GRDC data during late winter or spring. In most of these basins such as Columbia River, Upper Mississippi, and Great Lakes, the simulated precipitation is quite comparable to the observed during winter and spring, although a dry bias is found in the summer (Fig. 2). However, the simulated runoff does not capture the observed large spring peaks. This is likely related to errors in simulating snowpack and/or errors in the phase of precipitation due to a combination of model resolution and potential errors in representing snow 
Fig. 5 Long-term mean terrestrial water storage anomaly $\Delta \mathrm{S}$ (in $\mathrm{mm} /$ day) from GRACE data and three simulations for 13 regions. The long-term average is based on 1990/3-2001/2 for the simulations and 2003-2007 for the GRACE data
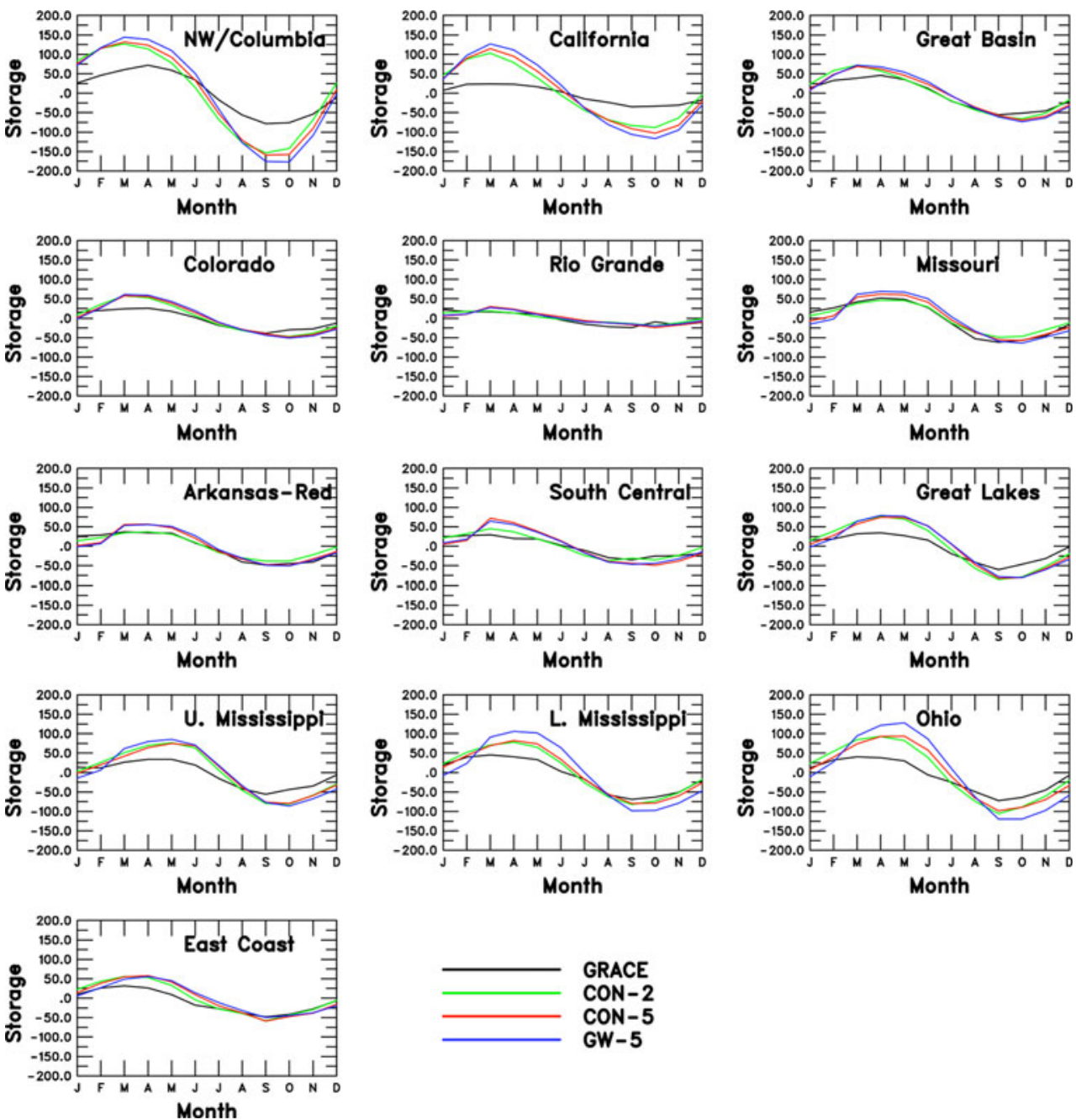

processes, so generally the simulated runoff is too high during winter (December-February) and too low in spring (March-May) when the observed runoff peaks. Leung et al. (2003) showed that the simulation of snowpack is very sensitive to model resolution, so the use of higher grid resolution can likely ameliorate this problem. In warmer basins such as Lower Mississippi and Ohio, the low bias in the simulated runoff is partly a result of the dry bias in precipitation, which exists throughout the year. However, comparing the ratio of runoff to precipitation from the simulations and observations (not shown) suggests that the partitioning of precipitation to runoff and soil water storage in the model and observation is inconsistent, particularly in Lower Mississippi. This could be related to the soil/vegetation properties prescribed in the model, or parameters used in the ARNO parameterization of subsurface flow and should be further investigated in the future.

To further evaluate the groundwater component simulated by the model, Fig. 5 shows a comparison of the terrestrial water storage anomaly $(\Delta S)$ from GW-5 and GRACE estimates for the 13 regions. Note that the $\Delta S$ from
GRACE is based on the average of 2003-2007 from three different estimates (CSR, GFZ, and JPL), whereas the GW5 simulated anomaly is an average of 1990-2001, so the difference in time periods could play a role for regions with large interannual or decadal variability. Figure 9 also includes $\Delta S$ derived from $\mathrm{CON}-2$ and $\mathrm{CON}-5$ to assess the impacts of soil depth and dynamic groundwater on terrestrial water storage.

The GRACE estimates show a similar seasonal cycle of $\Delta S$ across almost all regions. Generally, $\Delta S$ increases during winter to reach a maximum in March or April, and then decreases to reach a minimum in September. This seasonal cycle of $\Delta S$ is robust given the seasonal cycle of precipitation varies widely across the regions. The seasonal cycle of $\Delta S$ can be interpreted from the rate of change in water storage anomaly $(\Delta S / \Delta T)$, which can be derived from precipitation $(P)$, evapotranspiration $(\mathrm{ET})$, and runoff $(R)$ based on $\Delta S / \Delta T=P-\mathrm{ET}-R$. During winter, ET is small, so $\Delta S / \Delta T$ is dominated by the accumulation of $(P-R)$ stored as soil moisture. As temperature increases in spring and summer, ET increases and reaches a 
maximum in June and July. This increase in ET generally far exceeds $(P-R)$ so water storage is depleted in the summer. As the large demand of ET cannot be met by the available soil moisture later in the summer, ET is limited by soil moisture, and the water storage continues to decrease and reach a minimum in September. Therefore, to a large extent, the seasonal variations in $\Delta S$ are dominated by large seasonal changes in ET, which is shaped largely by the seasonal cycle of the net surface energy and water availability, especially in water-limited regions. While $\Delta S / \Delta T$ has a maximum and minimum in winter and summer, $\Delta S$ has a maximum and minimum in spring and fall.

Comparing with the GRACE estimates, the simulations generally have larger seasonal differences in $\Delta S$. It should be noted that similarly large positive bias in the seasonal range in NW/Columbia and California is also found in offline VIC simulation driven by observed meteorological forcing (Gao et al. 2009) with a $2 \mathrm{~m}$ soil depth. This highlights the challenges in simulating/prescribing precipitation and simulating soil hydrology, as well as potential problems in the GRACE estimates in regions of complex terrain. However, our simulations show larger seasonal ranges in many other basins than the GRACE estimates. A primary reason for the bias in seasonal storage is the negative bias in precipitation, which is most severe during summer and fall in many basins (Fig. 2). This dry bias leads to much reduced soil moisture in the summer and increases the seasonal range in $\Delta S$ in basins across the central US and Midwest.

Comparing the different simulations, it is clear that soil depth has some influence on the seasonal cycle of water storage. Both CON-5 and GW-5 show larger seasonal variations than observations and $\mathrm{CON}-2$, and the differences are larger in wetter regions such as NW/Columbia, California, and Ohio River basin. Such differences in the seasonal cycle of $\Delta S$ can be traced back to the large differences in seasonal runoff between CON-2 and CON-5/ GW-5, as shown in Fig. 3. Since a deeper soil column allows moisture to be stored during the wet season, this increases $\Delta S$ during winter and spring, but the increase in runoff during the dry season and the higher ET supported by higher soil moisture in the deeper soil reduce the water storage in the summer. Therefore CON-2 has a smaller seasonal range in $\Delta S$ that are closer to the GRACE estimates.

Comparing CON-5 and GW-5, the seasonal range in $\Delta S$ in wet regions is amplified further when groundwater table is simulated dynamically in GW-5. There are a few regions where the seasonal range in $\Delta S$ is reduced in GW-5 compared to CON-5. These include Rio Grande, South Central, and East Coast. On average, the seasonal range is larger in GW-5 than CON-5. Averaging over all the regions, the seasonal range of $\Delta S$ increases from 148 to $162 \mathrm{~mm}$, or roughly $10 \%$ from CON-5 to GW-5.

The simulated water storage is influenced by many factors including perhaps most importantly biases in simulated precipitation and uncertainties in soil properties and soil depth. Given the degree of freedom in a fully coupled land-atmosphere model forced only by global reanalysis atmospheric conditions at the lateral boundaries and sea surface temperature, these simulations provide an indication or upper limit of what may be expected in a free running global climate simulation.

\subsection{Soil moisture profile and groundwater table depth}

Figure 6 compares the observed soil moisture profiles from eight AmeriFlux stations with the GW-5 simulation. Table 3 lists the names, locations, vegetation classifications, and measurement depths of the stations used. The AmeriFlux stations record soil moisture at 4-6 depths up to $1 \mathrm{~m}$ deep. Data are available since 2004, so mean seasonal values are calculated by averaging the seasonal means between 2004 and 2006 for comparison with the long-term seasonal mean calculated from GW-5. Although soil moisture was not measured below $1 \mathrm{~m}$, we include the soil moisture profiles simulated for the whole 5-m column to show the variability of soil moisture profiles in locations with different groundwater table depths.

In Bondville and Fermi, Illinois, two pairs of measurements are available to show the large variations of soil moisture. For example, the observed soil moisture profiles are rather different between Bondville and Bondville Companion Site, showing generally wetter conditions at Bondville, with higher soil moisture values during winter and spring compared to the dryer conditions and higher soil moisture values during summer and fall at Bondville Companion Site. Similarly, large differences also exist between the vertical structures of soil moisture at the two Fermi sites with different vegetation (agriculture vs. prairie). This highlights the strong dependence of soil moisture on local soil/vegetation conditions and hence the challenge of using in situ measurements for comparison with climate simulations.

In the model simulation, soil moisture shows less vertical variations compared to observations. This could be related to discrepancy between point measurements and model simulation over a relative large grid. In addition, the observed soil moisture profiles represent averages over a much shorter time period than the model simulation, so large variability from year to year could lead to more structures in the vertical distribution of the observed profiles. Generally, soil moisture is higher during winter and spring and reaches a minimum during fall. The seasonal variations are larger near the surface and reduce to zero at 

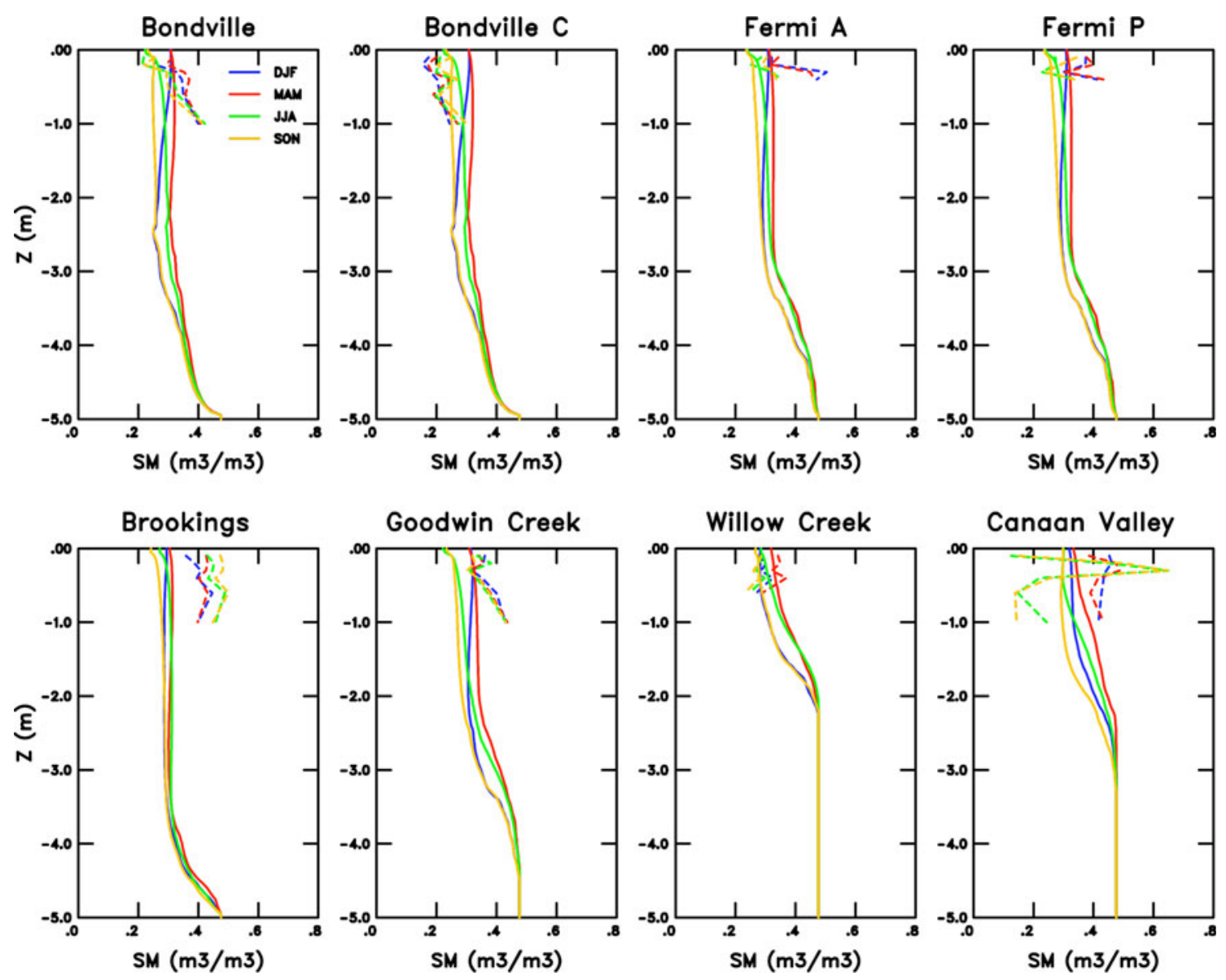

Fig. 6 Observed (dashed) and simulated (solid) mean soil moisture profile at 8 AmeriFlux stations for four seasons

Table 3 The names, locations, vegetation classification, and measurement depths of eight AmeriFlux stations used for comparison with the simulated soil moisture profiles

\begin{tabular}{llll}
\hline Station name & Location & Vegetation & Depths (cm) \\
\hline Bondville, IL & $40.00^{\circ} \mathrm{N}, 88.3^{\circ} \mathrm{W}$ & Croplands & $10,20,30,40,60,100$ \\
Bondville Companion Site, IL & $40.00^{\circ} \mathrm{N}, 88.30^{\circ} \mathrm{W}$ & Croplands & $10,20,30,40,60,100$ \\
Fermi Agricultural, IL & $41.86^{\circ} \mathrm{N}, 88.22^{\circ} \mathrm{W}$ & Croplands & $5,10,25,50$ \\
Fermi Prairie, IL & $41.84^{\circ} \mathrm{N}, 88.24^{\circ} \mathrm{W}$ & Grasslands & $5,10,25,50$ \\
Brookings, SD & $44.35^{\circ} \mathrm{N}, 96.83^{\circ} \mathrm{W}$ & Grasslands & $10,20,30,40,60,100$ \\
Goodwin Creek, MS & $34.25^{\circ} \mathrm{N}, 89.87^{\circ} \mathrm{W}$ & Grasslands & $10,20,30,40,60,100$ \\
Willow Creek, WI & $45.81^{\circ} \mathrm{N}, 90.08^{\circ} \mathrm{W}$ & Deciduous broadleaf forest & $5,10,20,50,100$ \\
Canaan Valley, WV & $39.06^{\circ} \mathrm{N}, 79.42^{\circ} \mathrm{W}$ & Grasslands & $10,20,30,40,60,100$ \\
\hline
\end{tabular}

or near the groundwater table. Overall, the simulated soil moisture values are comparable to the observations and show similar seasonal variations. In areas with shallow GWT, the simulated soil moisture profiles show a smooth transition from the surface to the groundwater table, and the soil moisture is constant below the GWT at the saturated values. For areas with groundwater table below $5 \mathrm{~m}$, since we impose a soil depth of $5 \mathrm{~m}$, the groundwater module forces saturation in the soil at $5 \mathrm{~m}$ and a small vertical gradient in soil moisture close to the boundary. By prescribing soil depth at $5 \mathrm{~m}$, the subsurface soil moisture would be wetter than it should be in regions where groundwater table is deep. This will have some impacts on the simulated surface water budgets and the simulated land-atmosphere feedbacks described in the paper. 

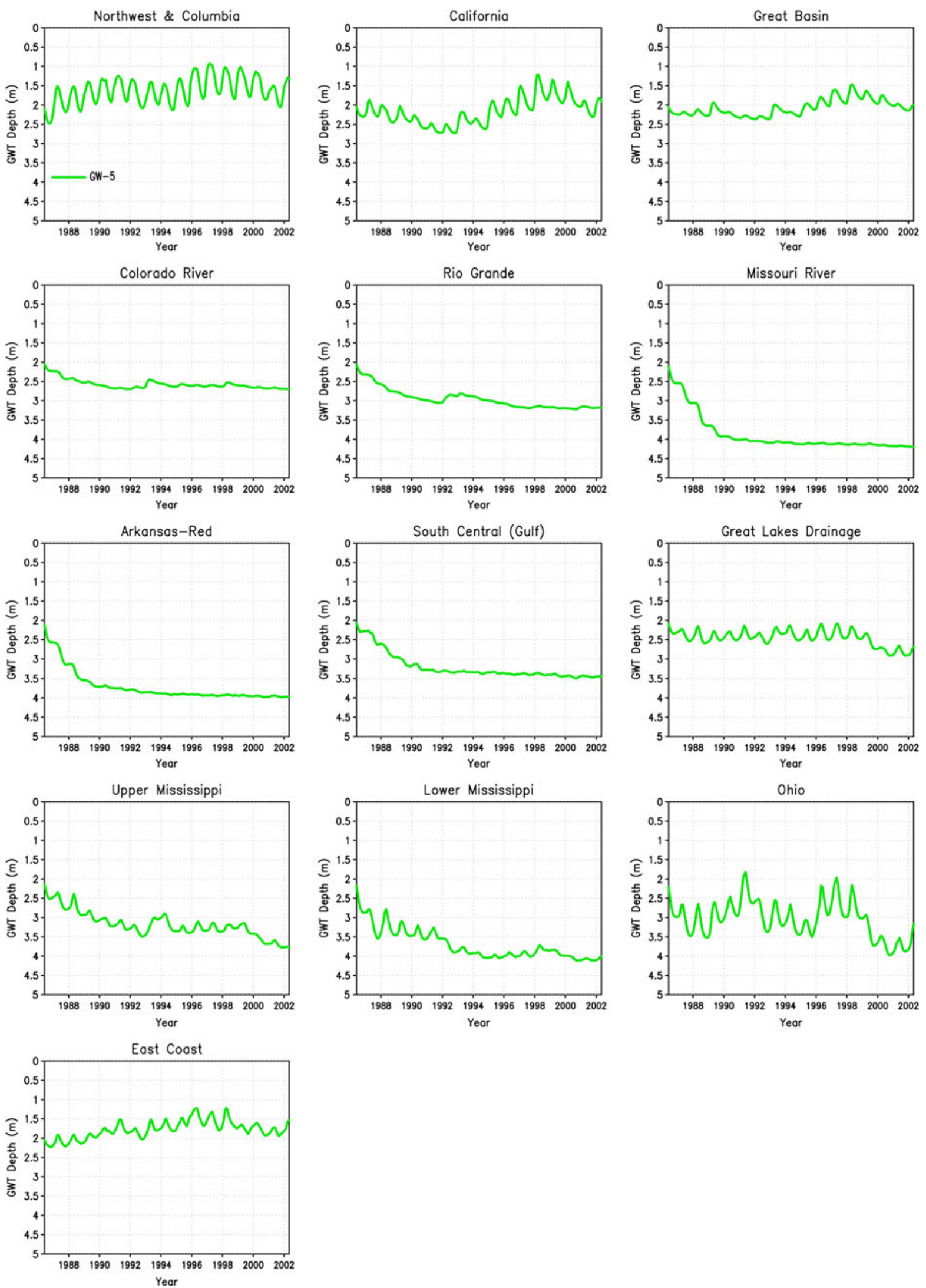

Fig. 7 Time series of monthly mean groundwater table depth (GWT) (m) in the GW-5 simulation averaged over 13 regions 
Figure 7 shows the monthly time series of groundwater table depth (GWT) simulated by GW-5 for the 13 regions. As mentioned earlier, the simulated groundwater table generally stabilized within 4 years of model spin up so model evaluation and analysis reported in this paper used only results from the last 12 years (after 1990). There are interesting regional differences that reflect the dominant influence of the climate forcing on the subsurface water component. In wet regions with large seasonal changes in precipitation such as NW/Columbia River, California, Ohio River, and East Coast, the simulation shows large variations in the GWT seasonally, but longer time scale variations reflecting the multi-year variability in precipitation are also noticeable. In the western US, the regional average GWT is relatively shallow and varies between 1 and $2.5 \mathrm{~m}$, as the region receives a large amount of precipitation during the cold season. The Ohio River basin instead receives most of its precipitation between March and June, and the GWT also displays significant temporal variability at the seasonal and interannual time scales.

In relatively dry regions such as the Rio Grande and Colorado River, seasonal variations are minimal in the GWT. We see clearly the influence of GWT initialization in the first few years, but the GWT stabilizes to a value that reflects both the influence of the climate forcing (precipitation in particular) and land surface properties. For example, the GWT is found to stabilize at a larger value (or deeper groundwater table) of about $4 \mathrm{~m}$ in the ArkansasRed River and Missouri River than Rio Grande and Colorado River, although annual precipitation amounts are clearly higher in the former two regions. This suggests that other factors such as soil properties and vegetation may play a larger role in determining the GWT for drier basins than for wetter basins.

Figure 8 shows the spatial distribution of the mean GWT from point measurements archived by US Geological
Survey. However, most sites only include a single or few time samples, so the data may be strongly influenced by seasonal and interannual variations. Comparing the observed GWT with the long term mean simulated GWT shown in Fig. 9, there are qualitative agreement between the simulation and observations in the east and west coasts where the GWT is generally lower (shallower) than other regions. Although the simulation did not capture the very deep GWT in Central and Southwest US, the GWT is deeper in those regions compared to other areas. Obvious reasons for disagreement between the simulated and observed GWT include sustained groundwater withdrawals that have occurred in those regions over the last few decades to meet the growing water demand, and mismatch of scales between point measurements and simulation at $60 \mathrm{~km}$ grid resolution. These effects show up clearly in Fig. 7 where large spatial variability occurs over short distances in regions such as southern California because some point measurements are reflecting anthropogenic effects. The use of a $5 \mathrm{~m}$ soil column in the model also limits the simulated GWT for comparison with observed data in regions that may naturally have a deeper groundwater table. This constraint can be relaxed by prescribing a deeper soil column in the future. Limitations of model representations as well as uncertainty in model inputs that characterize the vegetation and soil properties of the regions may also contribute to errors or uncertainties in the simulated GWT.

The comparison of observed and simulated groundwater table, runoff, water storage anomaly, and soil moisture profile points to the potential for improving the surface hydrology simulation by more careful calibration of the parameters used in the runoff parameterizations (e.g., $D_{\text {smax }}, D_{\text {s }}$, and $W_{\mathrm{s}}$ ) and spatially varying vegetation information (e.g., minimum stomatal resistance, root depth, etc.), soil properties (e.g., soil depth, saturated
Fig. 8 Observed groundwater table depth (m) from USGS unconfined aquifers and groundwater wells

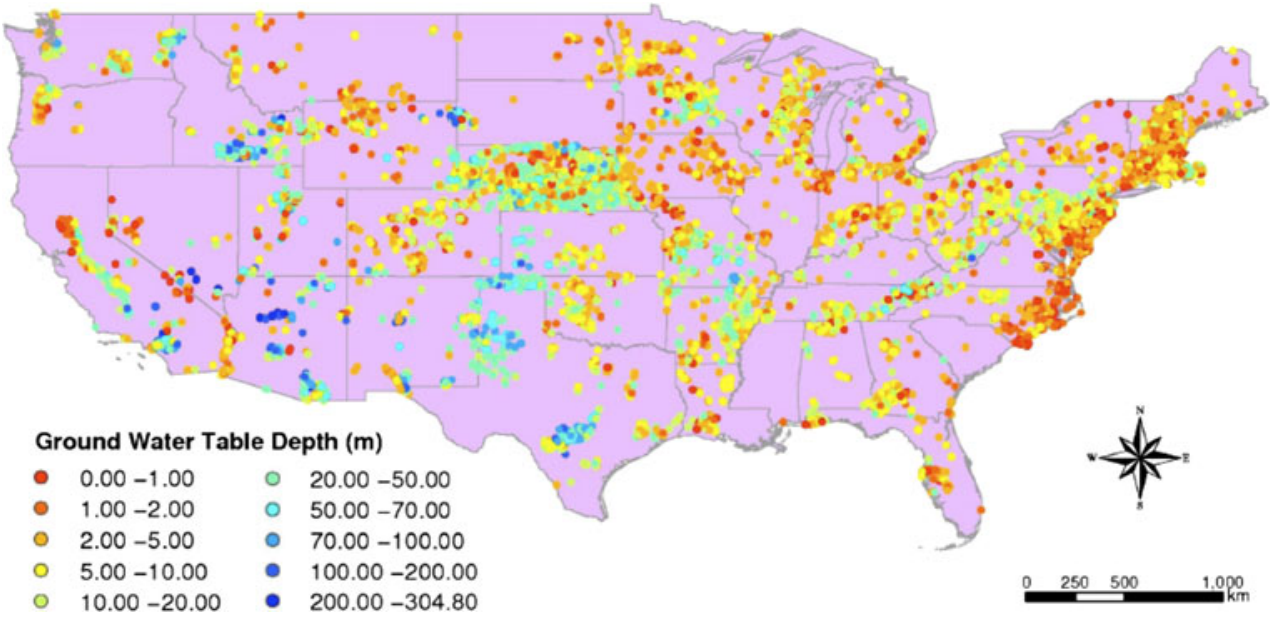


Fig. 9 Spatial distribution of long-term mean groundwater table depth $(\mathrm{m})$ averaged over 1990/3-2001/2 from GW-5 (top) and soil type (bottom). The number in each grid box indicates the USGS soil type. The latter is also shown in color for four groups of soil type defined in the text
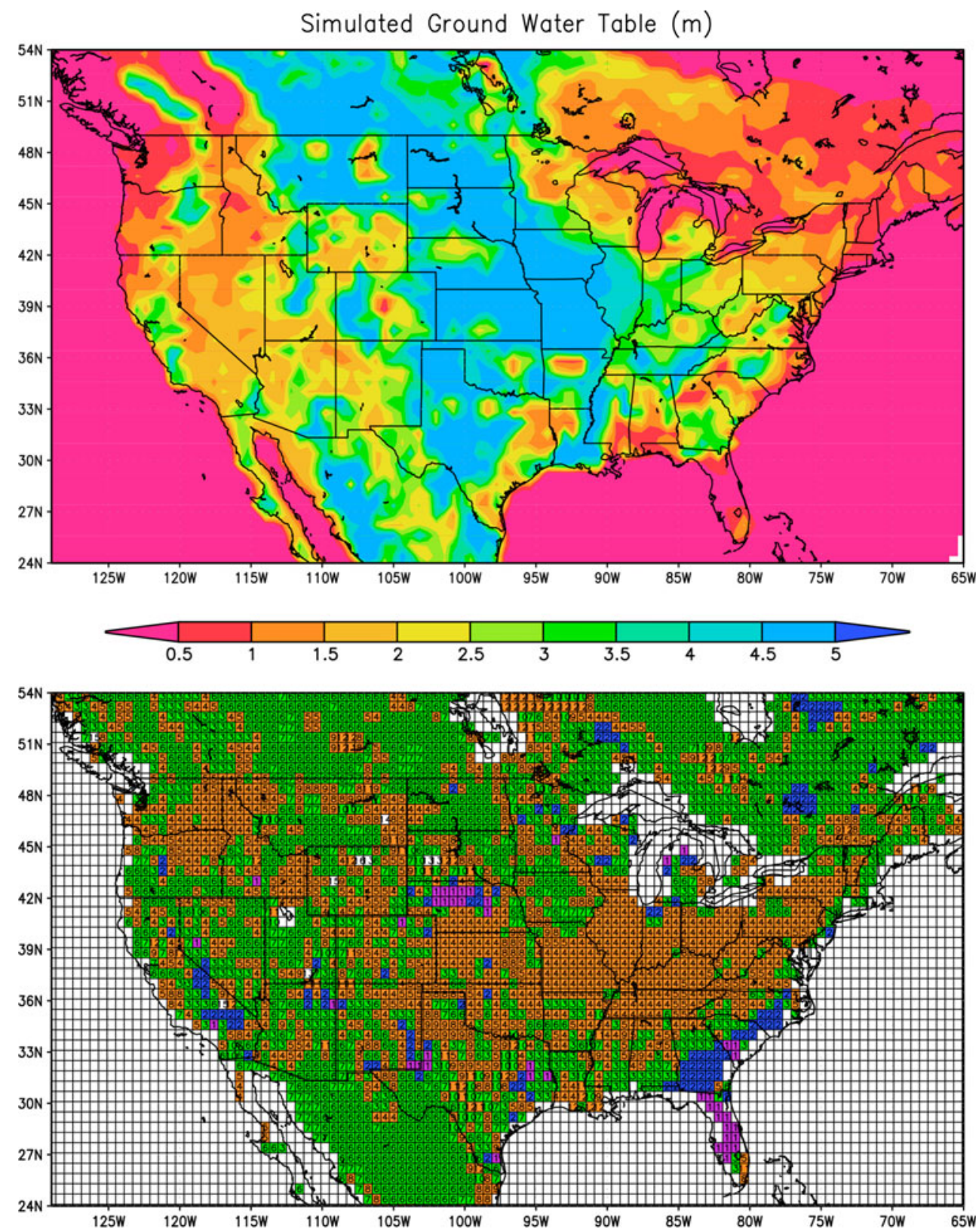

hydraulic conductivity, etc.), and topography (slope). In this study, VIC uses the ARNO formulation for subsurface flow, which includes two parameter values (i.e., $D_{\mathrm{s}}$ and $W_{\mathrm{s}}$ ) that have been tested for shallow soil depth such as $2 \mathrm{~m}$, and slope is assigned an arbitrarily low value commensurate with the model grid size rather than treated as a tuning parameter. The use of offline model forced by observed meteorology should provide useful constraints to assess the soil hydrology simulated by the model, as precipitation biases are likely to dominate the errors in surface hydrology in coupled land-atmosphere simulations.

\section{Influence of climate, soil, and vegetation on groundwater table depth}

To understand the role of climate forcing and land surface properties in determining the GWT, we compare the spatial distribution of the simulated GWT and soil type in Fig. 9. Note that the number in each grid cell of the soil map denotes the soil type defined in Table 2. To facilitate the discussion, we aggregate the soil types into 4 groups shown using color. The first group (purple) is consist of sand; the second group (blue) is consist of loamy sand; the third group (orange) is a combination of soil type $4,5,8,9,11$, 
and 12; the fourth group (green) is a combination of soil type $3,6,7$, and 10 . These groups roughly combine soils that have similar soil porosity and hydraulic conductivity (see Table 2).

Figure 9 shows that the simulated GWT generally has lower values in wetter regions such as the west coast, east coast, and the Great Lakes region. However, there are spatially coherent smaller scale structures that reflect the influence of soil property. For example, the GWT is extremely low in Florida, which is dominated by sandy (purple) and loamy sand (blue) soil. Note that loamy sand has higher hydraulic conductivity than sand (Table 2). Similarly in northern Nebraska and the area between Lake Michigan and Lake Huron, areas with sand and loamy sand coincide with the distinctly lower GWT compared to that of the surrounding areas. As discussed in Sect. 2.1, the hydraulic conductivity for sand is prescribed a very low value, so our simulations may not truly reflect the properties of sand. Nevertheless, our results highlight the important influence of soil properties on the GWT.

To summarize the influence of climate and soil property control on the simulated GWT, Fig. 10 shows the longterm mean GWT against the long-term annual mean precipitation for each model grid cell with soil type 3 (sandy loam) and 4 (silt loam). To facilitate comparison between the soil types, data points for the two soil types are fitted with a simple exponential function shown by the solid curves in Fig. 10. Our results show that precipitation has very strong control over the GWT at the long time scale. For both soil types (red and blue), the GWT decreases (i.e., becomes shallower) sharply with increasing precipitation.

Fig. 10 Long-term mean groundwater table depth $(\mathrm{m})$ versus the long-term mean precipitation $(\mathrm{mm} / \mathrm{day})$ in $\mathrm{GW}-5$ for grid cells with sandy loam (blue) and silt loam (red) soil within the model domain. Data points for the two groups of soil are fitted using simple exponential functions shown by the curves. Values for grass and shrub are shown by circles and crosses, respectively; dots are used for all other vegetation types
Of the soil properties defined by the soil type, soil porosity and hydraulic conductivity (Table 2) both exert strong influence on the groundwater table. As discussed in Sect. 2.1, subsurface flow is parameterized based on the ARNO formulation, where $D_{\text {smax }}$ was estimated as a product of the saturated hydraulic conductivity and the slope of the model grid cell. Because we used a very low value of 0.005 for slope due to the relatively large model grid size, our simulated subsurface runoff is generally rather low except in very wet regions such as the Pacific Northwest and California (Fig. 3). Therefore the simulated groundwater table is, to a larger degree, controlled by groundwater recharge (source) than subsurface runoff (sink), both of which depend on soil properties. Under this condition, silt loam (red) soil, which has high soil porosity and low hydraulic conductivity, has lower rate of water movement through the soil column by gravity and capillary action and therefore lower rate of recharge to groundwater that results in deeper groundwater table. In contrast, sandy loam soil (blue) has higher hydraulic conductivity and lower soil porosity compared to silt loam soil (red). This promotes higher recharge rate and shallower groundwater table.

From Fig. 10, we note that within each soil type (of the same color), there are clusters of points following different rates of GWT decay with precipitation. To assess the impacts of vegetation parameters on GWT, we use circle to represent grass and cross to represent shrub. Grid points for all other vegetation types are simply marked using dots to highlight the comparison between grass and shrub. Comparing grassland (vegetation type 7) across the two soil groups, we can see the separation between the red and blue

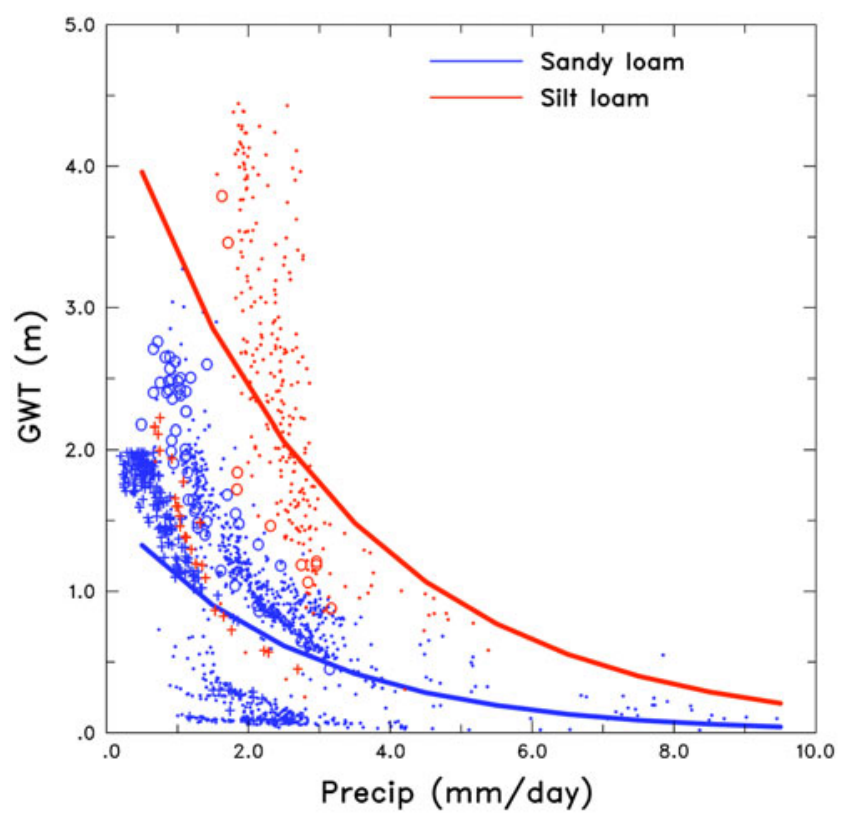


circles, showing that the GWT gets deeper from sandy loam (blue) to silty loam (red) soil. In addition, the GWT decreases at a faster rate with increasing precipitation for silty loam (red) soil than sandy loam (blue) soil. For the same soil type, however, the GWT for grass (e.g., blue circle) is generally deeper than that of shrub (blue cross). This shows that vegetation parameters also have important control on the GWT. From Table 1, shrub, for example, has much higher minimum stomatal resistance than grass (300 vs. $40 \mathrm{~s} / \mathrm{m}$ ). This can significantly reduce ET from shrub when precipitation is low and lead to a shallower GWT compared to grass.

\section{Feedbacks of groundwater table dynamics on climate through land-atmosphere interactions}

\subsection{Land-atmosphere interactions in model simulations}

Land surface and vegetation processes can exert a strong influence on the climate system through several landatmosphere interactions pathways. Broadly, they include the impacts of surface albedo and soil moisture on the surface energy balance and partitioning, near surface humidity, and boundary layer depth. Through changes in cloud, precipitation, and regional and large-scale circulation, the atmosphere modulates the energy and water budgets at the surface.

In the US, several studies have identified regions (or "hot spots") where land-atmosphere coupling may provide important feedbacks to the climate system (e.g., Koster et al. 2004, 2006; Zhang et al. 2008). Wet soils increase evapotranspiration and near surface humidity over land during daytime, which lowers the boundary layer depth and cloud base. The relationship between soil moisture and the evaporative fraction, which is defined as $\mathrm{LH} /(\mathrm{SH}+\mathrm{LH})$ and correlates well with the height of the cloud base, is a useful concept to determine the strength of land-atmosphere feedbacks (Betts 2004). Table 4 summarizes the relationship between monthly mean near surface soil moisture $(0-0.5 \mathrm{~m})$ and sensible heat flux $(\mathrm{SH})$, evaporative fraction $(\mathrm{EF})$, and precipitation $(P)$ from GW-5 averaged over 13 regions for the summer. The correlation coefficients are calculated based on monthly mean regional averages for June, July, and August between 1990 and 2001. All the correlation coefficients are statistically significant at the $90 \%$ confidence level except for two values marked by the parentheses.

Higher soil moisture generally results in lower SH and GWT, but higher EF and $P$. The highest correlation coefficients are typically found between soil moisture and EF, which is an indication of the strength of land-atmosphere
Table 4 Correlation coefficient between the monthly mean soil moisture from the surface to $0.5 \mathrm{~m}$ below with the monthly mean sensible heat flux (COR_SH), evaporative fraction (COR_EF), and precipitation (COR_P), and the summer mean LH $\left(\mathrm{W} / \mathrm{m}^{2}\right)$ averaged over 13 regions from the simulation GW-5 for the summer

\begin{tabular}{lcccc}
\hline Region & COR_SH & COR_EF & COR_P & LH \\
\hline NW/Columbia & -0.74 & 0.80 & 0.79 & 62.3 \\
California & -0.59 & 0.97 & 0.72 & 38.9 \\
Great Basin & 0.74 & 0.67 & 0.58 & 22.3 \\
Colorado & 0.49 & 0.35 & {$[-0.06]$} & 28.8 \\
Rio Grande & -0.42 & 0.72 & {$[0.23]$} & 34.1 \\
Missouri & -0.88 & 0.96 & 0.78 & 76.3 \\
Arkansas-Red & -0.74 & 0.89 & 0.45 & 67.6 \\
South Central & -0.79 & 0.87 & 0.39 & 74.4 \\
Great Lakes & -0.64 & 0.86 & 0.71 & 88.3 \\
U. Mississippi & -0.82 & 0.87 & 0.73 & 101.6 \\
L. Mississippi & -0.93 & 0.93 & 0.68 & 111.9 \\
Ohio & -0.81 & 0.86 & 0.71 & 117.2 \\
East Coast & -0.72 & 0.77 & 0.29 & 101.3 \\
\hline All the conrelation & coeficis & & &
\end{tabular}

All the correlation coefficients are statistically significant at the $90 \%$ confidence level except for the two numbers in parentheses

interactions, as discussed above. Among the 13 regions, the highest correlation between soil moisture and EF (correlation coefficient $>0.9$ ) is found in California, Missouri, and Lower Mississippi, and lower correlation is found in Colorado, Rio Grande, and Great Basin. Overall, the correlation is above 0.85 in all regions in the central US Regions with higher correlation across all variables $(\mathrm{SH}$, $\mathrm{EF}, P$, and GWT) include NW/Columbia, Missouri, Great Lakes, and Upper and Lower Mississippi. These regions coincide with the swath of areas across the northern US identified by Zhang et al. (2008) from observations and modeling that indicate stronger coupling between soil moisture and precipitation.

In contrast, semi-arid regions including Great Basin, Colorado, and Rio Grande all show relatively low correlation between soil moisture and SH or EF. Unlike all other regions, Great Basin and Colorado even show a positive correlation between soil moisture and SH. From Table 4, the summer mean LH in these basins is the lowest among the 13 regions. With ET limited by soil moisture, $\mathrm{SH}$ is controlled more by temperature rather than soil moisture. Thus in water limited region, soil moisture has little control on the partitioning of surface energy. In these regions, $P$ is controlled more by large-scale atmospheric moisture convergence (e.g., related to the North American summer monsoon) rather than evaporation from the surface, and soil moisture is quickly depleted after a precipitation event because the soil is dry. Therefore from both perspectives, the correlation between soil moisture and $P$ is very low. 
In between the northern regions with higher correlation between soil moisture and SH and EF and the semi-arid regions with lower correlation are regions such as Arkansas-Red, South Central, and East Coast where the correlation between soil moisture and SH or EF are relatively high, but the correlation between soil moisture and $P$ is relatively low. They represent regions where $P$ may be influenced both by large-scale circulation (e.g., moisture from the Gulf of Mexico) and the land surface.

The partition of surface energy between LH and $\mathrm{SH}$ is sensitive to soil moisture (except in very dry regions), so differences in soil depth and groundwater table dynamics can lead to changes in LH and SH. Figure 11 compares LH and $\mathrm{SH}$ in $\mathrm{CON}-2, \mathrm{CON}-5$, and GW-5 for 13 regions. The partitioning between $\mathrm{LH}$ and $\mathrm{SH}$ differs significant between wet and dry regions. Generally higher soil moisture in wet regions can support higher $\mathrm{LH}$, but the seasonality of precipitation is also important. For example, both NW/ Columbia and California are regions with very high precipitation during the cold season, but only part of the water is stored in the soil during summer. So LH in these regions is less than that in regions such as Missouri and Mississippi where precipitation amount is less but maximizes during the warm season. In semi-arid region, LH is much lower than SH. Comparing all three simulations, larger differences are found between CON-5 and GW-5, with the latter showing higher LH and lower SH in many regions. The differences between $\mathrm{CON}-2$ and $\mathrm{CON}-5$ are negligible because the soil moisture for the first two layers (between 0 and $0.5 \mathrm{~m}$ ) is comparable in the two simulations.

\subsection{Feedbacks of groundwater table dynamics on climate}

To assess the impacts of simulating groundwater table and its interactions with soil moisture, Fig. 12 compares the long-term summer mean soil moisture from 0 to $0.5 \mathrm{~m}$ and 0.5 to $5 \mathrm{~m}, \mathrm{EF}$ and precipitation simulated by $\mathrm{CON}-5$ and GW-5. Note that both simulations used a $5 \mathrm{~m}$ soil depth, so differences between these simulations can be attributed to the groundwater component. Figure 12 shows that groundwater table dynamics mainly influences the partitioning of soil water between the surface $(0-0.5 \mathrm{~m})$ and subsurface $(0.5-5 \mathrm{~m})$ compared to the 3-layer scheme that lumps soil moisture below $0.5 \mathrm{~m}$ into a single layer. In most areas, the soil moisture between 0 and $0.5 \mathrm{~m}$ is generally higher in GW-5 than CON-5, and vice versa for the soil moisture between 0.5 and $5 \mathrm{~m}$. The changes are reversed only in areas with very shallow GWT, as in northeast Canada and southeast US Areas where the differences between the GW-5 and CON-5 simulations are statistically significant at the $90 \%$ confidence level are marked by the black contour. The differences in soil moisture are especially high in regions such as Missouri River and Arkansas-Red where the groundwater table is deep. Incidentally the model simulated more realistic runoff in these regions (Fig. 4). As discussed in Sect. 5.2, soil water movement tends to be slower in these regions because of the soil properties. By allowing groundwater table dynamics to be simulated, GW-5 retains more moisture near the surface than $\mathrm{CON}-5$ that simulates only the bulk soil moisture in three layers.

For the large areas where soil moisture near the surface is increased, LH is generally enhanced and $\mathrm{SH}$ reduced in GW-5 (Fig. 11), so that in most regions both EF and precipitation increases in GW- 5 by up to 0.5 and $1 \mathrm{~mm} /$ day, respectively, compared to CON-5 in NW/Columbia, California, and Ohio, where the GWT has larger seasonal variations. However, the largest increase in precipitation is found in the central Plain, which is included in the black contour that marks the areas where precipitation differences between the GW-5 and CON-5 simulations are higher than the $75 \%$ confidence level, because the absolute increase in LH is larger. Smaller areas in Nebraska and Kansas show precipitation differences that are statistically significant even at the $90 \%$ confidence level. By simulating groundwater table dynamics and the associated impacts on soil moisture, the dry bias in the central Plain is slightly reduced. The changes in EF and precipitation are small in the semi-arid regions. For regions in the Southeast, Northeast, and near the Great Lakes where soil moisture changes are reversed, we see reductions in EF and precipitation. There are small areas over the ocean where precipitation changes are also quite large as changes in the land-sea temperature gradient influence atmospheric circulation and cloudiness in the coastal regions.

To further investigate the impacts of dynamically simulating groundwater table, we selected Missouri River for more in-depth comparison between CON-5 and GW5 because Table 4 shows that land-atmosphere interactions are stronger in this area. Figure 13 compares the change (GW-5 minus CON-5) in EF with changes in soil moisture between 0 and $0.5 \mathrm{~m}(\mathrm{SM})$, the fraction of soil moisture between 0 and $0.5 \mathrm{~m}$ to the column total soil moisture (SF), column integrated cloud liquid water path (CLD), diurnal temperature range (DTR), top-of-the-atmosphere (TOA) outgoing shortwave (SW) and longwave (LW) radiation, mean surface temperature (T), and the ratio of convective to total precipitation (CF) in Missouri River. Each point corresponds to a summer month (June-August) between 1990 and 2001. The correlation coefficient $(r)$ is listed above each figure.

From Fig. 13, we see that EF changes are indeed strongly correlated with soil moisture changes, but higher correlation is obtained between EF changes and SF changes (0.903) than SM changes for $0-0.5 \mathrm{~m}(0.820)$ or the 

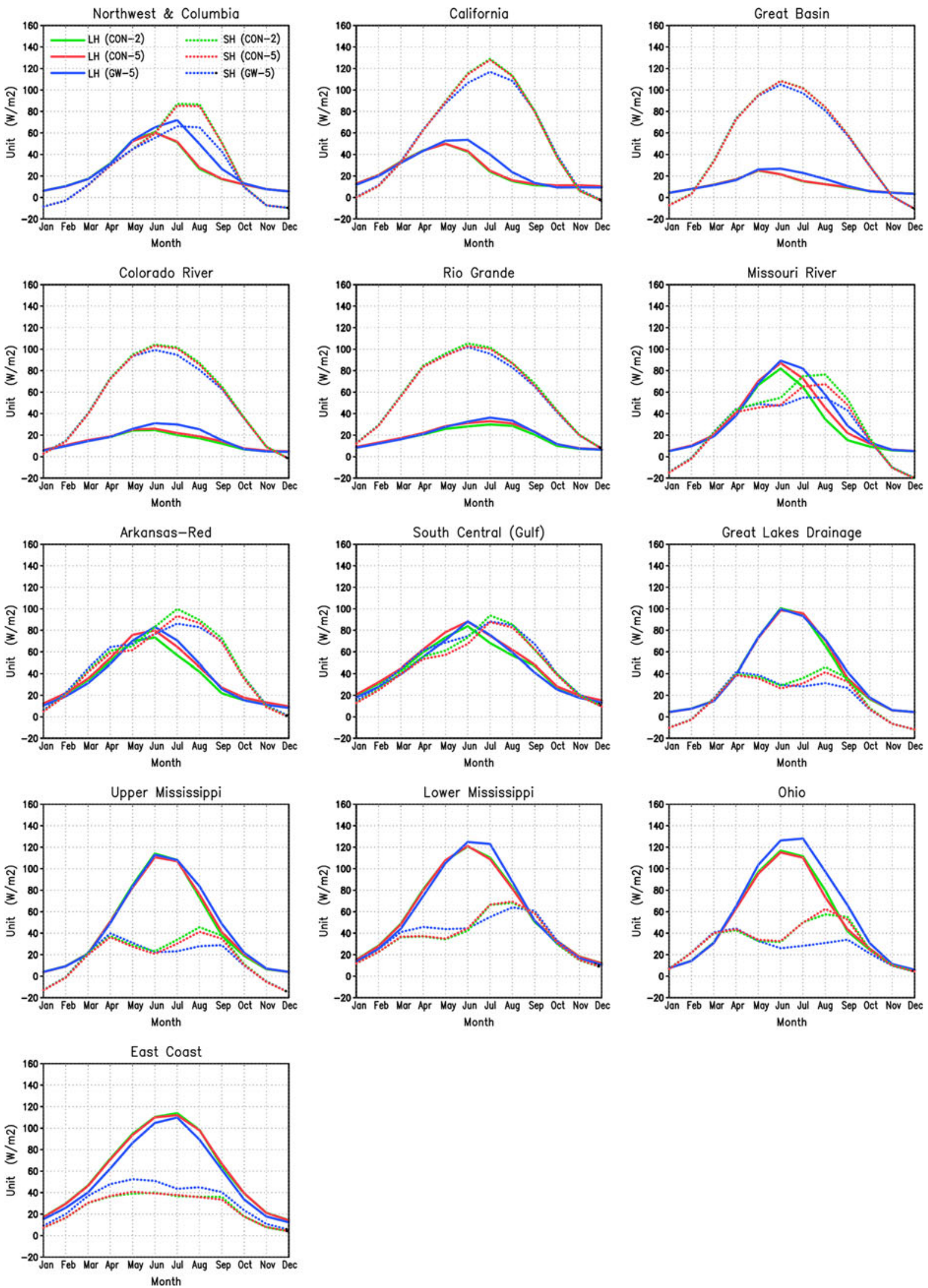

Fig. 11 Mean monthly latent heat flux $(\mathrm{LH})$ and sensible heat flux $(\mathrm{SH})$ from CON-2, CON-5, and GW-5 for 13 regions. Units are W/m² 
JJA $0-0.5 m$ Soil Moisture $(\mathrm{mm}) \quad$ GW-5 - CON-5

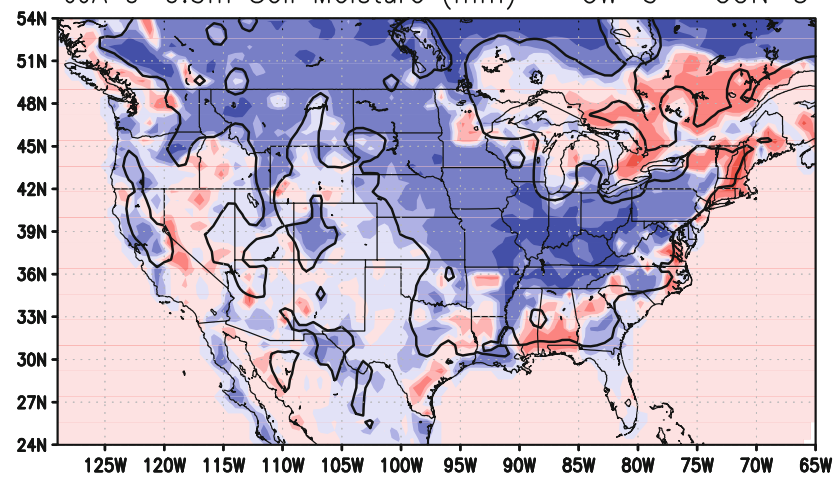

\begin{tabular}{l|lll|lllll}
-60 & -40 & -20 & -10 & 0 & 10 & 20 & 40 & 60
\end{tabular}

JJA $0.5-5 m$ Soil Moisture $(\mathrm{mm}) \quad$ GW-5 $-\mathrm{CON}-5$

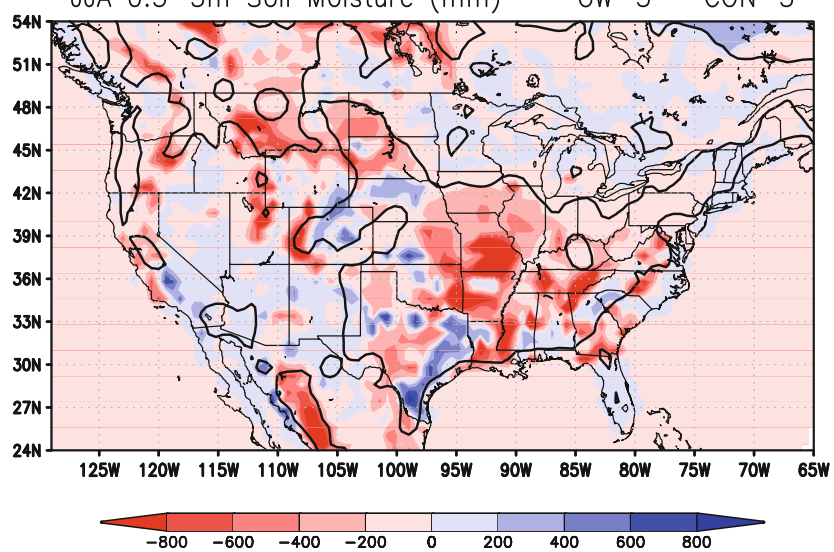

Fig. 12 Long-term summer mean changes in soil moisture for soil between 0 and $0.5 \mathrm{~m}$ (top left) and 0.5 and $5 \mathrm{~m}$ (bottom left), EF (top right) and precipitation (bottom right) between CON-5 and GW-5 (i.e., GW-5 minus CON-5) for 13 regions. Units are $\mathrm{mm}$ for soil

whole column (0.769). This shows that changes in the partitioning of soil water between the surface and subsurface due to groundwater table dynamics has the most important influence on $\mathrm{EF}$ or the partitioning of sensible and latent heat fluxes. Although surface soil moisture can directly influence evaporation from bare ground, vegetation can regulate ET in a more complex way that depends on soil moisture in both the surface and subsurface, besides other factors such as solar radiation and surface temperature and humidity.

After establishing the role of groundwater table dynamics on partitioning of soil moisture and surface fluxes, we determine how changes in partitioning of surface fluxes influence atmospheric processes. From Fig. 13, an increase in EF is accompanied by an increase in CLD, which reduces DTR as more clouds reduce the daily maximum temperature and increase the daily minimum temperature. Consistent with the increase in CLD is an increase in SW, as solar radiation is reflected by the
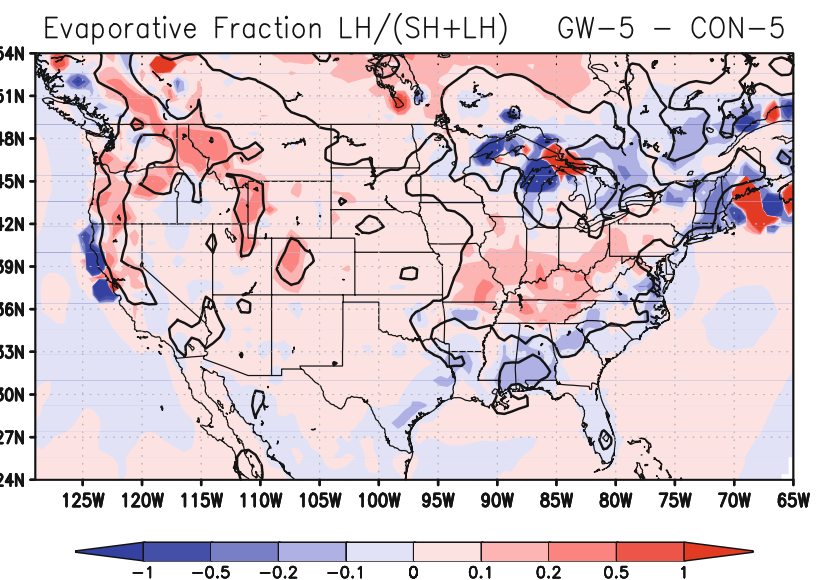

JJA Precipitation ( $\mathrm{mm} /$ day) $\mathrm{GW}-5-\mathrm{CON}-5$

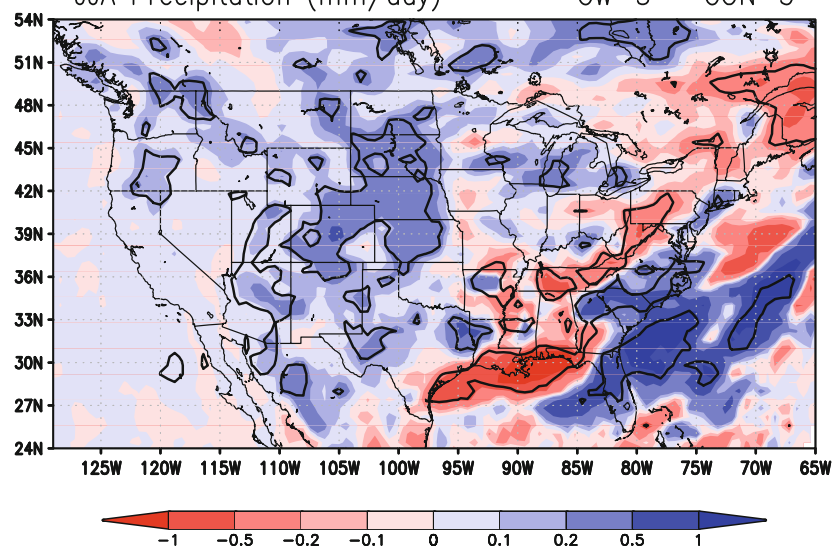

moisture, fraction for $\mathrm{EF}$, and $\mathrm{mm} /$ day for precipitation. The black contours marked the areas where the differences between the GW-5 and CON-5 simulations are statistically significant at the $90 \%$ level for soil moisture and $\mathrm{EF}$ and $75 \%$ level for precipitation, respectively

presence of more clouds. The correlation coefficient between EF and SW is higher than that between EF and CLD, showing more direct influence of EF on the energy budget than cloud water content through changes in cloud fraction. A decrease in LW implies that cloud top height or cloudiness increases as EF increases from CON-5 to GW5. These correlations suggest that increased EF leads to deeper convection and/or more cloudiness, which may increase precipitation. Indeed, both convective and nonconvective precipitation are higher in GW-5 compared to CON- 5 by $10-15 \%$, but the correlation between the change in $\mathrm{EF}$ and non-convective rain (0.561) is higher than that between EF and convective rain (0.278). Higher correlation is actually obtained by correlating changes in EF and the ratio of convective to total precipitation $(-0.689)$, as shown in Fig. 13. This shows that EF has a stronger influence on the partitioning of convective versus nonconvective rain rather than the total rainfall, as the latter may include remote influence such as circulation changes, 
Fig. 13 Comparison of changes in $\mathrm{EF}$ (in fraction) with changes in soil moisture between 0 and $0.5 \mathrm{~m}(\mathrm{SM})\left(\right.$ in $\left.\mathrm{m}^{3} / \mathrm{m}^{3}\right)$, ratio of soil moisture between 0 and 0.5 and total soil moisture (SF) (in fraction), column integrated cloud liquid water path (CLD) (in $10^{-1} \mathrm{~mm}$ ), diurnal temperature range (DTR) (in ${ }^{\circ} \mathrm{C}$ ), top-of-the-atmosphere shortwave (SW) and longwave $(\mathrm{LW})$ radiation (in $\left.\mathrm{W} / \mathrm{m}^{2}\right)$, mean surface temperature $(\mathrm{T})\left(\right.$ in $\left.{ }^{\circ} \mathrm{C}\right)$, and ratio of convective to total precipitation (CF) in Missouri River
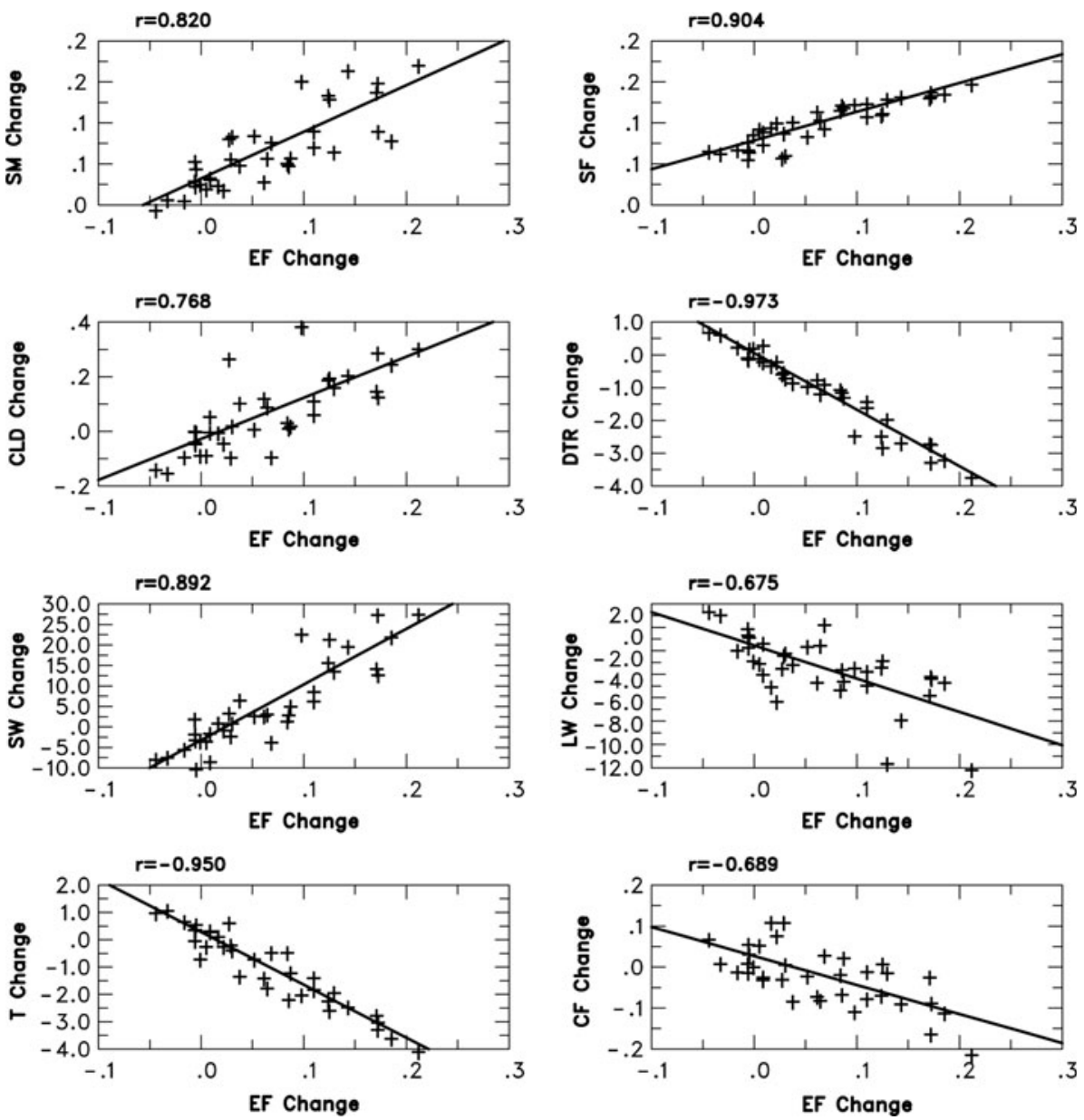

which may enhance or reduce precipitation in different ways. This latter result, however, could be dependent on the convection parameterization used in this study.

\section{Summary and discussion}

Using a regional climate model, three simulations have been performed to assess the influence of climate, soil, and vegetation on groundwater table dynamics, and its potential feedbacks to regional climate through land-atmosphere interactions. Our analysis shows that precipitation has a dominant influence on the spatial and temporal variations of groundwater table depth. The simulated GWT decreases sharply with increasing precipitation. However, our simulation also shows some distinct spatial variations that are related to soil and vegetation properties. Soil with low porosity and high hydraulic conductivity increases the rate of water movement through the soil by gravity and capillary action, and favors higher recharge to the groundwater table and hence shallower GWT, given the prescribed subsurface flow parameters. Vegetation properties such as minimum stomatal resistance and root fraction and depth are also found to have important influences on the GWT, and notable differences are found between grass and shrub. Topographic gradient should also play an important role in controlling the GWT, but such effects are not simulated in this study because we prescribed a uniform slope across the model domain. In addition, we used a very small value for the slope because of the large grid size; with $D_{\text {smax }}$ prescribed as a product of hydraulic conductivity and slope, this reduces the impacts of soil property and landscape on subsurface flow, and increases the sensitivity of groundwater table depth to groundwater recharge relative to subsurface flow.

To assess the impacts of simulating groundwater table dynamics, we compared two simulations, CON-5 and GW5 , with and without groundwater table dynamics. The longterm mean total soil moisture, surface fluxes, runoff, and precipitation for CON-5 and GW-5 are comparable. This shows that introducing groundwater table dynamics does not drastically change the surface hydrology and surface water budget for the VIC model with the prescribed vegetation and soil information used in this study. However, groundwater table dynamics can have important influences in some regions such as Missouri River, where analysis 
indicates stronger coupling between land and atmosphere processes. In such regions, anomalies of soil moisture are found to correlate strongly with the evaporative fraction, which changes the near surface humidity, boundary layer height, and cloud base to potentially influence precipitation.

Comparing CON-5 and GW-5, we find that groundwater table dynamics mainly influence the partitioning between soil water in the surface $(0-0.5 \mathrm{~m})$ and subsurface $(0.5-$ $5 \mathrm{~m}$ ) rather than total soil moisture based on the prescribed vegetation, soil, and slope information used in this study. This result, however, may depend on the prescribed parameters (e.g., root depth, root distribution, minimum stomatal resistance, hydraulic conductivity, $D_{\text {smax }}$, etc.) and the formulations (e.g., transpiration, subsurface flow, etc.) used in this study. In most areas, groundwater table dynamics increases surface soil moisture at the expense of the subsurface. The only exceptions are regions with very shallow groundwater table. The change in soil water partitioning is found to strongly correlate with the partitioning of surface sensible and latent heat fluxes. Generally EF is higher during the summer when groundwater table dynamics is included, which increases the ratio of surface to total soil moisture. Higher EF is accompanied by increased cloudiness, reduced diurnal temperature range, cooler surface temperature, and higher cloud top or deeper convection, as reflected in reductions of outgoing longwave radiation by up to $12 \mathrm{~W} / \mathrm{m}^{2}$. Therefore, our results show a clear pathway of how groundwater table dynamics influence cloudiness and precipitation through changes in the partitioning of latent and sensible heat fluxes.

The relatively weak impacts of groundwater table dynamics on precipitation amount may be related to the dry bias in the model simulations during summer and fall. A large fraction of precipitation during summer is convective. In Missouri River, for example, convective precipitation accounts for $30-90 \%$ of the total precipitation in our model simulations during June-August. The impacts of groundwater table dynamics on precipitation may depend on the convective parameterization used in the model. Our simulations used the Kain-Fritsch convective parameterization (Kain and Fritsch 1993), where convective adjustment is determined by mass rearrangement starting at the surface. Thus the Kain-Fritsch scheme should be responsive to surface forcing such as surface humidity that is influenced by EF. Indeed we find statistically significant correlations between changes in EF and outgoing longwave radiation associated with deeper convection. However, the precipitation produced by a convection scheme is highly parameterized, so the links from changes in EF to convective precipitation could still be weak, despite apparent links have been established between the changes in EF and convection. Lastly, the low correlation between the change in $\mathrm{EF}$ and total precipitation could be reflecting changes in the large-scale circulation, for example associated with increased surface pressure due to the cooler temperature (up to $4^{\circ} \mathrm{C}$ for some summer months in Fig. 11) that influences precipitation in a different way.

This study has demonstrated the feasibility of simulating groundwater table dynamics to represent the two-way coupling between surface and subsurface water and land and atmosphere in a climate model. An important implication of our results is that groundwater table dynamics can influence the partitioning of soil water in the surface and subsurface, and this has effects on the partitioning of surface energy fluxes, which influences atmospheric processes. This feedback is stronger in regions with deeper groundwater table, because the interactions between surface and subsurface water are weak when the groundwater table is deep. This essentially increases the sensitivity of the surface soil moisture to precipitation anomalies, and therefore enhances the land surface feedbacks to the atmosphere through changes in soil moisture and evaporative fraction. This result needs to be further investigated in the future to determine its sensitivity to soil and vegetation parameters including soil depth and root fraction and depth, and more realistic topographic effects on subsurface runoff. As soil and vegetation properties affect groundwater table depth, land use change can alter the groundwater table and influence the ability of the land surface to respond to climate anomalies such as prolonged drought conditions. Similarly, withdrawal of groundwater can significantly lower the groundwater table to amplify the sensitivity of land surface response and feedback to the climate system.

To more accurately assess the role of groundwater table dynamics on climate, and to improve climate and drought prediction at the seasonal to decadal time scales, we need improvements in several areas including data used to prescribe land properties (e.g., soil depth and soil and vegetation properties), model's ability to simulate precipitation, and representation of anthropogenic effects such as groundwater withdrawal that limits the influence of groundwater table dynamics on soil moisture and surface fluxes. On the former, we will explore the use of different land surface properties data sources and assess the impacts of soil, vegetation, topography, and the ARNO subsurface flow parameters on simulating groundwater table dynamics and implications to its feedbacks to the atmosphere. Furthermore, as pointed out by Todini (1995) and Todini and Dumenill (1999), a major disadvantage of the ARNO parameterization is its lack of physical grounds, and therefore requires calibration using long term streamflow records. This weakness limits its applications in ungauged basins and climate models. Moreover, the ARNO model does not consider the spatial variability of subsurface flow, 
which is inconsistent with other VIC formulations and ignores the GWT that can now be calculated by VIC explicitly. To address these issues, Huang et al. (2008) proposed a new subsurface flow parameterization that is physically based, and incorporates spatial variability of topography, recharge, and water table status. We will test and evaluate this new parameterization in the future.

Acknowledgments This study was supported by the Department of Energy (DOE) bilateral agreement between DOE and China Ministry of Science and Technology on regional climate research and by the DOE Climate Change Prediction Program (CCPP) on abrupt climate change to the Pacific Northwest National Laboratory and the University of Pittsburgh (DE-FG-02-08ER64586). We thank Dr. Huilin Gao for sharing her postprocessed GRACE data averaged over the 13 regions used in our analysis. Pacific Northwest National Laboratory is operated for the US DOE by Battelle Memorial Institute under contract DE-AC06-76RLO330 1830.

Open Access This article is distributed under the terms of the Creative Commons Attribution Noncommercial License which permits any noncommercial use, distribution, and reproduction in any medium, provided the original author(s) and source are credited.

\section{References}

Anyah RO, Weaver CP, Miguez-Macho G, Fan Y, Robock A (2008) Incorporating water table dynamics in climate modeling: 3. Simulated groundwater influence on coupled land-atmosphere variability. J Geophys Res 113. doi:10.1029/2007JD009087

Betts AK (2004) Understanding hydrometeorology using global models. Bull Am Meteorol Soc doi:10.1175/BAMS-85-11-1673

Beven KJ, Kirby MJ (1979) A physically-based variable contributing area model of basin hydrology. Hydrol Sci Bull 24:43-69

Chambers DP (2006) Evaluation of new GRACE time-variable gravity data over the ocean. Geophys Res Lett 33:L17603

Chen F, Dudhia J (2001) Coupling an advanced land surface hydrology model with the Penn State-NCAR MM5 modeling system. Part I: model implementation and sensitivity. Mon Weather Rev 129(4):569-585

Chen X, Hu Q (2004) Groundwater influences on soil moisture and surface evaporation. J Hydrol 297:285-300

Cherkauer KA, Lettenmaier DP (2003) Simulation of spatial variability in snow and frozen soil. J Geophys Res 108 (D22). doi:10.1029/2003JD003575

Cosby BJ, Hornberger GM, Clapp RB, Ginn TR (1984) A statistical exploration of the relationships of soil moisture characteristics to the physical properties of soils. Water Resour Res 20(6): $682-690$

Dickinson RE, Henderson-Sellers A, Kennedy PJ (1993) BiosphereAtmosphere Transfer Scheme (BATS) Version 1e as coupled to the NCAR Community Climate Model. NCAR Technical Note NCAR/TN-387 + STR, 72 pp

Dorman JL, Sellers PJ (1989) A global climatology of albedo, roughness length and stomatal resistance for atmospheric general circulation models as represented by the Simple Biosphere Model (SiB). J Appl Meteorol 28:833-855

Fan Y, Miguez-Macho G, Weaver C, Walko R, Robock A (2007) Incorporating water table dynamics in climate modeling. Part I: water table observations and the equilibrium water table. J Geophy Res 112:D10125. doi:10.1029/2006JD008111
Francini M, Pacciani M (1991) Comparative analysis of several conceptual rainfall-runoff models. J Hydrol 122:161-219

Gao H, Tang Q, Ferguson CR, Wood EF, Lettenmaier DP (2009) Estimating the water budget of major U.S. river basins via remote sensing. Int J Remote Sens (submitted)

Grell G, Dudhia J, Stauffer DR (1994) A description of the fifth generation Penn State/NCAR mesoscale model (MM5). NCAR Technical Note. NCAR/TN-398-IA, National Center for Atmospheric Research, Boulder, CO, 117 pp

Gutowski WJ, Vorosmarty CJ, Person M, Otles Z, Fekete B, York JA (2002) Coupled land-atmosphere simulation program (CLASP): calibration and validation. J Geophys Res 107 (D16): Art. No. 4283

Huang M, Liang X, Liang Y (2003) A transferability study of model parameters for the variable infiltration capacity land surface scheme. J Geophys Res 108(D22):8864. doi:10.1029/2003 JD003676

Huang M, Liang X, Leung LR (2008) A generalized subsurface flow parameterization considering subgrid spatial variability of topography and recharge. J Hydrometeorol 9(6):1151-1171

Jackson TJ (2002) Remote sensing of soil moisture: implications for groundwater recharge. Hydrogeol J 10(1):40-51

Jiang X, Niu GY, Yang ZL (2009) Impacts of vegetation and groundwater dynamics on warm season precipitation over the central United States. J Geophys Res 114:D06109. doi: 10.1029/2008JD010756

Kain JS, Fritsch JM (1993) Convective parameterization in mesoscale models: the Kain-Fritsch scheme. The representation of cumulus convection in numerical models, Meteorological Monographs No. 46, American Meteorological Society 165-170

Kanamitsu M, Ebisuzaki W, Woollen J, Yang S-K, Hnilo J, Fiorino JM, Potter JP (2002) NCEP-DOE AMIP-II reanalysis (R-2). Bull Am Meteorol Soc 83:1631-1643

Koster RD et al (2004) Regions of strong coupling between soil moisture and precipitation. Science 305:1138-1140. doi:10.1126/ science. 1100217

Koster RD et al (2006) GLACE: the global land-atmosphere coupling experiment. Part I: overview. J Hydrometeorol 7:590-610

Leung LR, Ghan SJ (1998) Parameterizing subgrid orographic precipitation and surface cover in climate models. Mon Weather Rev 126(12):3271-3291

Leung LR, Qian Y, Bian X (2003) Hydroclimate of the western United States based on observations and regional climate simulation of 1981-2000. Part I: seasonal statistics. J Clim 16(12):1892-1911

Liang X, Xie Z (2001) A new surface runoff parameterization with subgrid-scale soil heterogeneity for land surface models. Adv Water Resour 24:1173-1193

Liang X, Lettenmaier DP, Wood EF, Burges SJ (1994) A simple hydrologically based model of land surface water and energy fluxes for general circulation models. J Geophys Res 99(D7): $14415-14428$

Liang X, Wood EF, Lettenmaier DP (1999) Modeling ground heat flux in land surface parameterization schemes. J Geophys Res 104:9581-9600

Liang X, Xie Z, Huang M (2003) A new parameterization for groundwater and surface water interactions and its impact on water budgets with the VIC land surface model. J Geophys Res 108(D16):8613. doi:10.1029/2002JD003090

Liang X, Leung LR, Huang M, Qian Y, Wigmosta MS, Matanga GB, and Mathews D (2006) PUB working group on orographic precipitation, surface and groundwater interactions, and their impacts on water resources. In: Sivapalan M, Wagener T, Uhlenbrook S, Zehe E, Lakshmi V, Liang X, Tachikawa Y, Kumar P (eds) Predictions in ungaged basins: promises and progress. IAHS Publication 303, 520 pp 
Mahfouf JF, Manzi AO, Noilhan J, Giordani H, Deque M (1995) The land surface scheme ISBA within the Meteo-France climate model ARPEGE. Part I: implementation and preliminary results. J Clim 8:2039-2057

Maurer EP, Wood AW, Adam JC, Lettenmaier DP, Nijssen B (2002) A long-term hydrologically based dataset of land surface fluxes and states for the conterminous United States. J Clim 15:32373251

Maxwell RM, Kollet SJ (2008) Interdependence of groundwater dynamics and land-energy feedbacks under climate change. Nat Geosci 1:865-869

Maxwell RM, Miller NL (2005) Development of a coupled land surface and groundwater model. J Hydrometeorol 6(3):233-247

Miguez-Macho G, Fan Y, Weaver CP, Walko R, Robock A (2007) Incorporating water table dynamics in climate modeling: 2. Formulation, validation, and soil moisture simulation. J Geophys Res 112:D13108. doi:10.1029/2006JD008112

Miller DA, White RA (1998) A conterminous United States multilayer soil characteristics data set for regional climate and hydrology modeling. Earth Interactions 2. Available online at http://EarthInteractions.org

National Research Council (2003) Groundwater fluxes across interfaces. The National Academy Press, $85 \mathrm{pp}$

Niu G-Y, Yang Z-L, Dickinson RE, Gulden LE, Hua S (2006) Development of a simple groundwater model for use in climate models and evaluation with gravity recovery and climate experiment data. J Geophy Res 112 (07103). doi:10.1029/ 2006JD007522

Qian Y, Leung LR (2007) A long-term regional simulation and observations of the hydroclimate in China. J Geophys Res 112:D14104. doi:10.1029/2006JD008134

Rodell M, Famiglietti JS (2001) An analysis of terrestrial water storage variations in Illinois with implications for the gravity recovery and climate experiment (GRACE). Water Resour Res 37(5):1327-1339

Rodell M, Famiglietti JS, Chen J, Seneviratne SI, Viterbo P, Holl S, Wilson CR (2004) Basin scale estimates of evapotranspiration using GRACE and other observations. Geophy Res Lett 31:L20504. doi:10.1029/2004GL020873

Salvucci GD, Entekhabi D (1995) Hilslope and climatic controls of hydrological fluxes. Water Resour Res 31:1725-1739

Scanlon BR, Mace RE, Barrett ME, Smith B (2002) Can we stimulate regional groundwater flow in a karst system using equivalent porous media models? Case study, Barton Springs Edwards aquifer, USA. J Hydrol 276:137-158

Sophocleous M (2004) Climate change: why should water professionals care? Ground Water 42(5):637

Taylor KE, Williamson D, Zwiers F (2000) The sea surface temperature and sea-ice concentration boundary conditions for AMIP II simulations. PCMDI Report No. 60, Program for Climate Model Diagnostics and Intercomparison. Lawrence Livermore National Laboratory, Livermore, CA, 25 pp

Todini E (1995) New trends in modelling soil processes from hillslope to GCM scales. In: Oliver HR, Oliver SA (eds) The role of water and the hydrological cycle in global change global environmental change, NATO ASI Series, Series I, vol 31. Springer, New York, p 317

Todini E (1996) The ARNO rainfall-runoff model. J Hydrol 175: 339-382

Todini E, Dumenill L (1999) Estimating large-scale runoff. In: Browning KA, Gurney RJ (eds) Global energy and water cycles. Cambridge University Press, Cambridge, pp 265-281

Troen I, Mahrt L (1986) A simple model of the atmospheric boundary-layer-sensitivity to surface evaporation. Bound Layer Meteorol 37:129-148

Walko RL et al (2000) Coupled atmosphere-biophysics-hydrology models for environmental modeling. J Appl Meteorol 39: 931-944

Yeh PJF, Eltahir EAB (2005a) Representation of water table dynamics in a land surface scheme: 1. Model development. J Clim 18(12):1861-1880

Yeh PJF, Eltahir EAB (2005b) Representation of water table dynamics in a land surface scheme: 2. Subgrid heterogeneity. J Clim 18(12):1881-1901

York JP, Person M, Gutowski WJ, Winter TC (2002) Putting acquifers into atmospheric simulation models: an example from Mill Creek Watershed, northeastern Kansas. Adv Water Res 25:221-238

Yuan X, Xie Z, Zheng J, Tian X, Yang Z (2008) Effects of water table dynamics on regional climate: a case study over East Asian monsoon area. J Geophys Res 113:D21112. doi:10.1029/ 2008JD010180

Zhang J, Wang WC, Leung LR (2008) Contribution of landatmosphere coupling to summer climate variability over the contiguous United States. J Geophys Res 113:D22109. doi: 10.1029/2008JD010136 